\title{
Fexofenadine and Rosuvastatin Pharmacokinetics in Mice with Targeted Disruption of Organic Anion Transporting Polypeptide 2B1 ${ }^{\text {s }}$
}

\author{
Samantha Medwid, ${ }^{1}$ Mandy M.J. Li, ${ }^{1}$ Michael J. Knauer, ${ }^{1}$ Kathleen Lin, Sara E. Mansell, \\ Crystal L. Schmerk, Catherine Zhu, Katelyn E. Griffin, Mohamed D. Yousif, George K. Dresser, \\ Ute I. Schwarz, Richard B. Kim, and Rommel G. Tirona
}

Department of Physiology and Pharmacology (S.M., M.M.J.L., M.J.K., K.L., C.Z., K.E.G., M.D.Y., U.I.S., R.B.K., R.G.T.), and Division of Clinical Pharmacology, Department of Medicine (S.E.M., C.L.S., G.K.D., U.I.S., R.B.K., R.G.T.), University of Western Ontario, London, Ontario, Canada

Received April 16, 2019; accepted May 20, 2019

\begin{abstract}
Organic anion transporting polypeptide 2B1 (OATP2B1) is a widely expressed membrane transporter with diverse substrate specificity. In vitro and clinical studies suggest a role for intestinal OATP2B1 in the oral absorption of medications. Moreover, OATP2B1 is highly expressed in hepatocytes where it is thought to promote liver drug clearance. However, until now, a shortcoming of studies implicating OATP2B1 in drug disposition has been a lack of in vivo models. Here, we report the development of a knockout (KO) mouse model with targeted, global disruption of the S/co2b1 gene to examine the disposition of two confirmed mOATP2B1 substrates, namely, fexofenadine and rosuvastatin. The plasma pharmacokinetics of intravenously administered fexofenadine was not different between $\mathrm{KO}$ and wildtype (WT) mice. However, after oral fexofenadine administration, KO mice had $70 \%$ and $41 \%$ lower maximal plasma concentration $\left(C_{\text {max }}\right)$ and area under the plasma concentration-time curve ( $A \cup C_{0-\text { last }}$ ) than WT mice, respectively. In WT mice, coadministration of fexofenadine with grapefruit juice (GFJ) or apple juice (AJ) was associated with reduced $C_{\max }$ by $80 \%$ and $88 \%$, respectively, while
\end{abstract}

the $\mathrm{AUC}_{0-\text { last }}$ values were lower by $35 \%$ and $70 \%$, respectively. In KO mice, AJ coadministration reduced oral fexofenadine $\boldsymbol{C}_{\max }$ and AUC $_{0-\text { last }}$ values by $67 \%$ and $59 \%$, respectively, while GFJ had no effects. Intravenous and oral rosuvastatin pharmacokinetics were similar among WT and KO mice. We conclude that intestinal OATP2B1 is a determinant of oral fexofenadine absorption, as well as a target for fruit juice interactions. OATP2B1 does not significantly influence rosuvastatin disposition in mice.

\section{SIGNIFICANCE STATEMENT}

A novel mouse model with targeted disruption of the S/co2b1 gene revealed that OATP2B1 is a determinant of oral absorption but not systemic disposition of fexofenadine, as well as a target of fruit juice interactions. Rosuvastatin oral and intravenous pharmacokinetics were not dependent on OATP2B1. These findings support the utility of the S/co2b1 KO mouse model for defining mechanisms of drug disposition at the intersection of in vitro and clinical pharmacology.

\section{Introduction}

Organic anion transporting polypeptide (OATP) 2B1 was discovered almost two decades ago and originally characterized as a membrane transporter with broad tissue distribution and relatively narrow substrate specificity (Tamai et al., 2000; Kullak-Ublick et al., 2001). Indeed, OATP2B1 is expressed in brain, liver, kidney, heart, lung, placenta, small intestine, skeletal muscle, pancreas, coronary artery, platelets, and macrophages (Tamai et al., 2000; Kullak-Ublick et al., 2001; St-Pierre

This work was supported by the Canadian Institutes of Health Research [Grants MOP-86522 and MOP-136909 (to R.G.T.)].

${ }^{1}$ S.M., M.M.J.L., and M.J.K. contributed equally to this work.

https://doi.org/10.1124/dmd.119.087619.

S This article has supplemental material available at dmd.aspetjournals.org. et al., 2002; Grube et al., 2006; Niessen et al., 2009; Seki et al., 2009; Knauer et al., 2010; Hussner et al., 2015; Kim et al., 2017; Nakano et al., 2019). However, in vitro studies have since shown OATP2B1 has remarkably broad substrate specificity ranging from molecules that are small (5-aminosalicylate), large (bromosulfophthalein), peptidic (substance P), hydrophilic (benzylpenicillin), lipophilic (amiodarone), uncharged (abiraterone), anionic (rosuvastatin), cationic (celiprolol), or zwitterionic (fexofenadine) (Tirona and Kim, 2014). Given its expression in key tissues of drug disposition and its diversity of substrates, OATP2B1 is thought to play at role in the pharmacokinetics of many drugs.

Perhaps the most influential support for the contribution of OATP2B1 in drug disposition comes from results of clinical food-drug and drugdrug interaction studies. The first and prototypical example is the fruit juice/fexofenadine interaction (Dresser et al., 2002). Fexofenadine is a

ABBREVIATIONS: $\mathrm{AJ}$, apple juice; $\mathrm{AUC}_{0-\infty}$, area under the concentration-time curve from time zero to infinity; $\mathrm{AUC}_{0-\text { last }}$, area under the concentration-time curve from time zero to the last sampling time; BCRP, Breast Cancer Resistance Protein; $\mathrm{CL}_{\text {plasma, }}$ plasma clearance; GFJ, grapefruit juice; HEK293, human embryonic kidney 293; HEK293T, human embryonic kidney 293 type T; KO, knockout; KOMP, Knockout Mouse Project; LC-MS/MS, liquid chromatography-tandem mass spectrometry; MDCKII, Madin-Darby canine kidney type II; mOATP, mouse organic anion transporting polypeptide; $\mathrm{mOCT}$, mouse organic cation transporter; $\mathrm{mPMAT}$, mouse plasma membrane monoamine transporter; $\mathrm{m} / \mathrm{z}$, massto-charge ratio; OATP, organic anion transporting polypeptide; OCT, organic cation transporter; rOATP, rat organic anion transporting polypeptide; $\mathrm{T}_{\max }$, time to maximum plasma concentration; $\mathrm{t}_{1 / 2}$, terminal half-life; WT, wild type. 
nonmetabolized, zwitterionic antihistamine that is remarkably well absorbed after oral administration (bioavailability of 30\%). When taken with grapefruit juice (GFJ), orange juice, or apple juice (AJ), fexofenadine plasma concentrations are dramatically reduced by $70 \%-80 \%$, with the strongest effects seen with AJ (Dresser et al., 2002). For GFJ, the major flavonoid, naringin, is the main constituent involved in the fexofenadine interaction (Bailey et al., 2007). Subsequent studies have found that absorption of other non- or poorly metabolized drugs such as talinolol (Schwarz et al., 2005), celiprolol (Lilja et al., 2003), atenolol (Jeon et al., 2013), aliskiren (Tapaninen et al., 2011) elvitegravir (Yonemura et al., 2018), and levothyroxine (Lilja et al., 2005) are also reduced when taken with fruit juices. The mechanism of fruit juice interactions with nonmetabolized drugs originally focused on OATP1A2 (Dresser et al., 2002), but many investigators are unable to consistently demonstrate that OATP1A2 is expressed in the gastrointestinal tract (Drozdzik et al., 2014). Therefore, attention has turned to OATP2B1 as the potential target of fruit juice/drug interactions since it is expressed in the small intestine, transports affected drugs including fexofenadine (Nozawa et al., 2004), and its transport activity is inhibited by fruit juice constituents in vitro (Satoh et al., 2005; Shirasaka et al., 2013). With respect to clinical drug-drug interactions, intestinal OATP2B1 has been implicated in the $50 \%$ reduction in bioavailability of oral rosuvastatin when coadministered with the OATP2B1 inhibitor ronacaleret (Johnson et al., 2017). Rosuvastatin is a poorly metabolized, hydrophilic drug whose disposition is influenced by hepatic OATP1B1/OATP1B3 and the intestine/liver efflux transporter Breast Cancer Resistance Protein (BCRP, also $A B C G 2$ ). Since experiments showed that neither OATP1B1/OATP1B3 nor BCRP were relevant to the ronacaleret interaction, it was concluded that rosuvastatin oral absorption is dependent on intestinal OATP2B1 (Johnson et al., 2017).

While there is growing evidence to support OATP2B 1 as a clinically relevant drug transporter, there are several examples of in vitro/clinical disconnects that challenge this notion. For instance, there are some poorly metabolized OATP2B1 substrates such as rosuvastatin and pravastatin that are not subject to significantly reduced oral absorption when taken together with fruit juices in clinical studies (Lilja et al., 1999; Kashihara et al., 2017). Additionally, a recent study showed that the major clinical drug interaction between atenolol and apple juice is not related to OATP2B1 since the drug is not a substrate and osmolarity may be a contributing factor (Funai et al., 2019). Another potentially disconcerting observation are reports that show that OATP2B1 is localized to the basolateral (Mooij et al., 2016; Keiser et al., 2017) rather than the apical (luminal) membrane of enterocytes (Kobayashi et al., 2003), casting doubt on a role in oral drug absorption and fooddrug interactions.

For the most part, the current concept of a possible link between OATP2B1 and its functions in pharmacokinetics has relied on associations between in vitro transporter pharmacology and tissue expression with clinical observations. A significant shortcoming of OATP2B1 pharmacology studies has been, until now, the lack of in vivo models that could be applied to expose mechanisms at the systems level. Here, we report the development of a mouse model with disruption of the gene encoding OATP2B1 (Slco2b1). We found that mouse OATP (mOATP) 2B1 affects the disposition of fexofenadine but not rosuvastatin. Furthermore, we show that mOATP2B1 is a target for fruit juice/fexofenadine pharmacokinetic interactions in vivo.

\section{Materials and Methods}

\section{Reagents}

$\left[{ }^{3} \mathrm{H}\right]$-fexofenadine (78 Ci/mmol, $99.7 \%$ radiochemical purity) was custom synthesized by Quotient Bioresearch (Fordham, Cambridgeshire, UK) by nonspecific labeling. $\left[{ }^{3} \mathrm{H}\right]$-rosuvastatin $(5 \mathrm{mCi} / \mathrm{mmol}, 99 \%$ radiochemical purity $)$ was purchased from American Radiolabeled Chemicals (St. Louis, MO). $\left[{ }^{3} \mathrm{H}\right]-$ bromosulfophthalein $(10.6 \mathrm{Ci} / \mathrm{mmol}, 99.5 \%$ radiochemical purity) was obtained from Moravek (Brea, CA). [ $\left.{ }^{3} \mathrm{H}\right]$-estrone-3-sulfate $(54.3 \mathrm{Ci} / \mathrm{mmol},>97 \%$ radiochemical purity) was purchased from PerkinElmer (Woodbridge, ON, Canada). Unlabeled fexofenadine, d6-fexofenadine, rosuvastatin, and d6-rosuvastatin were purchased from Toronto Research Chemicals (Toronto, ON). Concentrated $(4 \times)$ GFJ (Minute Maid, 100\% grapefruit juice frozen concentrate) and concentrated $(4 \times)$ AJ (no name, apple juice, frozen concentrate) were acquired from Walmart (London, ON) and Real Canadian Superstore (London, ON), respectively. The same GFJ and AJ stocks were used for all fruit juice experiments. All other chemicals, unless otherwise stated, were obtained from Sigma-Aldrich (St. Louis, MO).

\section{Plasmids}

Expression plasmids in pCMV6 vector for mOATP2B1 (NM_001252530) and mOATP1A5 (NM_130861) were obtained from Origene (Rockville, MD). Employing polymerase chain reaction with the Expand Long Template Polymerase Chain Reaction System (Roche Applied Science, Indianapolis, IN), other expression plasmids for mOATP1A1, mOATP1A4, mOATP1A6, mouse organic cation transporter (mOCT) 1, mOCT3, and mouse plasma membrane monoamine transporter (mPMAT) were developed by amplification of open reading frame cDNA from mouse small intestine, liver, or kidney cDNA (BioChain Institute, Inc., Newark, CA) using the following primers:

mOATP1A1 (forward) 5'-ACCATGGAAGAAACAGAGAAAAAGGTTGC-3' and (reverse) 5'-TTACAGCTTAGTTTTCAGTTCTCCATCG-3'; mOATP1A4 (forward) 5'-GTTCAAAGAATAGACATTTGGAGACAATC-3' and (reverse) 5'-AAACTAGTGACATGTGCGTTCTGGTTC-3';

mOATP1A6 (forward) 5'-AAGAACAAAATGGGAGAACCTGGGAAA-3' and (reverse) 5'-GAAACCTCATTACAGCTTAGTTTTCAG-3';

mOCT1 (forward) 5'-TACCCAGCCATGCCCACCGTGGACGAT-3' and (reverse) 5'-GCATCCCTGTCAGGTATGTGGGGATTT-3'; mOCT3 (forward) 5'-GGGCGCACCATGCCCACGTTCGACCAGGCA-3' and (reverse) 5'-ACAGGGGCCTCAGACATCAGAAGTAGAAAC-3'; mPMAT (forward) 5'-TGAACTGCCATGGGCTCTATCGGAAGCCAG-3' and (reverse) 5'-CCCGGCTCAGGGACCGACAGGGATGGAGTC-3'

The resulting amplicons were cloned into either pEF6/V5-His-TOPO or pcDNA3.1/V5-His-TOPO expression plasmids (Invitrogen, Burlington, ON)

\section{Transient Expression of Mouse Drug Transporters in Cultured Cells}

HeLa and human embryonic kidney 293 (HEK293) type T (HEK293T) cells were purchased from American Type Culture Collection (Manassas, VA) for use in transient transfection studies. HeLa and HEK293T cells were cultured in Dulbecco's modified Eagle's medium (Thermo Fisher Scientific, Grand Island, NY) supplemented with $10 \% \mathrm{FBS}, 100 \mathrm{U} / \mathrm{ml}$ penicillin, $100 \mu \mathrm{g} / \mathrm{ml}$ streptomycin, and $2 \mathrm{mM} \mathrm{L}$-glutamine (Invitrogen), at $37^{\circ} \mathrm{C}$ and $5 \% \mathrm{CO}_{2}$. For transport experiments, HeLa cells were seeded on regular 12 -well plates $\left(2.5 \times 10^{5}\right.$ cells/well), while HEK293T were seeded on poly-L-lysine-coated 12-well plates $\left(4.0 \times 10^{5}\right.$ cells/well). After 48 hours, cells were transfected with blank insert expression plasmids (control) or expression plasmids containing transporter cDNA inserts ( $1 \mu \mathrm{g}$ DNA/well) using Lipofectamine 3000 (Invitrogen) in OptiMEM (Thermo Fisher Scientific) for HEK293T cells or according to our previously described method (Cvetkovic et al., 1999) for HeLa cells. Cells were incubated for 16 hours prior to transport experiments.

\section{Stable Expression of Mouse OATP2B1 in Cultured Cells}

Madin-Darby canine kidney type II (MDCKII) cells were cultured in Dulbecco's modified Eagle's medium, 10\% FBS, $100 \mathrm{U} / \mathrm{ml}$ penicillin, $100 \mu \mathrm{g} / \mathrm{ml}$ streptomycin, and $2 \mathrm{mM} \mathrm{L-glutamine}$ and transfected with pCMV6-mOATP2B1 expression plasmid using Lipofectamine 3000 . Cell clones were obtained by a dilution method in 96-well plates under selection with geneticin $(800 \mu \mathrm{g} / \mathrm{ml}$; Invitrogen). The clone with the highest transport activity toward $[3 \mathrm{H}]$-estrone sulfate (hereafter, referred to as MDCKII-mOATP2B1) was expanded and maintained in geneticin selection media. For transport experiments, MDCKIIcontrol and MDCKII-mOATP2B1 cells were grown on 12-well plates (seeding density of $7.5 \times 10^{5}$ cells/well). After 48 hours, medium was replaced with that 
containing sodium butyrate $(25 \mathrm{mM})$ to increase transporter gene expression. Cells were then maintained for 24 hours prior to transport experiments.

\section{Immunofluoresence Microscopy of Cultured Cells and Liver}

Cellular expression and localization of mOATP2B1 in MDCKII cells and mouse liver was determined by immunofluorescence microscopy. For cells, MDCKIIcontrol and MDCKII-mOATP2B1 were cultured on Falcon four-chamber glass culture slides (ThermoFisher Scientific). After fixation with $4 \%$ paraformaldehyde, cells were permeabilized in $0.3 \%$ Triton X-100 in PBS and then blocked with $2 \%$ bovine serum albumin in PBS. Formalin-fixed, paraffin-imbedded mouse livers were dewaxed in xylene and graded ethanol solutions and then rehydrated in water. Antigen retrieval occurred in Tris-EDTA buffer $(\mathrm{pH} 9)$ with boiling in a microwave for 20 minutes. Tissue was blocked with $2 \%$ bovine serum albumin in PBS. Prepared tissues and cells were then incubated with custom-made, polyclonal, rabbit mOATP2B1 antibodies that were developed (Invitrogen) using the protein peptide sequence near the N-terminus (MGTEDMHERKVSVEPQD), which is present in both major mOATP2B1 protein variants (NP_001239459 and NP_780525). Anti-rabbit Alexa Fluor 488 (Invitrogen) secondary antibodies were applied and slides were mounted with VECTASHIELD containing nuclear 4',6diamidino-2-phenylindole stain (Vector Laboratories, Burlingame, CA). Epifluorescence microscopy was performed on a Nikon Eclipse 80i instrument.

\section{Western Blot Analysis}

Cell and tissue homogenates were prepared in Pierce IP Lysis Buffer (ThermoFisher) and proteins (50 $\mu \mathrm{g} /$ well) were separated by SDS-PAGE using $4 \%-12 \%$ gradient gels (NuPage; Invitrogen). After transfer to polyvinylidene difluoride membranes, blots were probed with custom rabbit polyclonal antibodies against mouse OATP2B1 (Invitrogen), glyceraldehyde-3-phosphate dehydrogenase (Abcam, Cambridge, MA), or actin (Santa Cruz, Dallas, TX) and visualized using horseradish peroxidase-labeled anti-rabbit antibodies (Cell Signaling, Danvers, MA) and chemiluminescence (Amersham ECL Select; GE Healthcare, Mississauga, ON) on an ImageQuant LAS 500 instrument (GE Healthcare).

\section{Solute Transport by Mouse Drug Transporters In Vitro}

Control and transporter-transfected MDCKII and HeLa cells were plated onto 12-well culture plates for solute uptake experiments. [3H]-fexofenadine, $[3 \mathrm{H}]$-rosuvastatin, $[3 \mathrm{H}]$-bromosulfophthalein, $[3 \mathrm{H}]$-estrone-3-sulfate, and/or unlabeled fexofenadine or rosuvastatin were dissolved in Krebs-Henseleit buffer $\left(1.2 \mathrm{mM} \mathrm{MgSO}_{4} \bullet 7 \mathrm{H}_{2} \mathrm{O}, 0.96 \mathrm{mM} \mathrm{KH}_{2} \mathrm{PO}_{4}, 4.83 \mathrm{mM} \mathrm{KCl}, 118 \mathrm{mM} \mathrm{NaCl}\right.$, $1.53 \mathrm{mM} \mathrm{CaCl}{ }_{2} \bullet 2 \mathrm{H}_{2} \mathrm{O}, 23.8 \mathrm{mM} \mathrm{NaHCO} 3,12.5 \mathrm{mM}$ 4-[2-hydroxyethyl]-1piperazineethanesulfonic acid, and $5 \mathrm{mM}$ glucose in water) at $\mathrm{pH} 6$ with the exception of experiments with mouse organic cation transporter (OCT) 1 and OCT3 transporters, where $\mathrm{pH} 7.5$ was used. In the context of OATP2B1, previous reports have demonstrated substrate-dependent stimulation of transporter activity by acidic extracellular milieu (Kobayashi et al., 2003; Nozawa et al., 2004; Visentin et al., 2012). The drug dose $(400 \mu \mathrm{l})$ was applied to cultured cells for 5-10 minutes at $37^{\circ} \mathrm{C}$ and $5 \% \mathrm{CO}_{2}$. Thereafter, cells were washed three times rapidly with ice-cold PBS. To quantify cellular radioactive drug accumulation, cells were lysed using $1 \mathrm{ml}$ of $1 \%$ SDS in water (v/v) and intracellular radioactivity was measured by liquid scintillation spectrometry (Tri-Carb 3900TR; Perkin Elmer, Waltham, MA). For the experiments with unlabeled fexofenadine or rosuvastatin, the cells were lysed using $400 \mu \mathrm{l}$ of acetonitrile spiked with internal standard d6-fexofenadine $(10 \mathrm{ng} / \mathrm{ml})$ or d6-rosuvastatin $(20 \mathrm{ng} / \mathrm{ml})$. Cell lysates were centrifuged for 10 minutes at $13,500 \mathrm{rpm}$ in a microcentrifuge and supernatants were dried in a SpeedVac (ThermoFisher) at $45^{\circ} \mathrm{C}$. Residues were analyzed for fexofenadine or rosuvastatin by the liquid chromatography-tandem mass spectrometry (LC-MS/MS) methods described subsequently. For studies in MDCKII cells, transport activity in each well was corrected for protein content as determined by the Pierce BCA Protein Assay Kit (ThermoFisher).

\section{Targeted Disruption in OATP2B1 in Mice}

Slco2b $1^{\text {tmla(KOMP)Wtsi }}$ mice were generated in collaboration with the Knockout Mouse Project (KOMP) at University of California, Davis (Davis, CA). National Institutes of Health grants to Velocigene at Regeneron Inc. (U01HG004085) and the CSD Consortium (U01HG004080) funded the generation of gene-targeted embryonic stem cells for 8500 genes in the KOMP Program, which were archived and distributed by the KOMP Repository at University of California, Davis, and Children's Hospital Oakland Research Institute (Oakland, CA; U42RR024244). For more information or to obtain KOMP products, the reader is referred to www.komp.org. In this mouse model, a gene trap cassette was inserted into the Slco2b1 gene in intron 3 of C57BL/6J mice by homologous recombination in embryonic stem cells to produce global knockdown of OATP2B1 gene expression. As shown in Results, OATP2B1 was undetectable in all tissues examined; therefore, for the purpose of this report we will refer to the homozygous Slco $2 b 1^{\text {tmla(KOMP)Wtsi }}$ mice as OATP2B1 knockout (KO) mice, i.e., mice with targeted disruption of Slco2b1. Wild-type (WT) C57BL/6 mice (Jackson Laboratories, Bar Harbor, MA) and KO mice were housed in a specific pathogen-free barrier facility in a temperature-controlled environment with a 12-hour light/dark cycle and received a standard diet (2018 Teklad Global 18\% protein rodent diet; Harlan Laboratories, Madison, WI) and water ad libitum. For genotyping, DNA was extracted from whole blood or liver using the MagNA Pure system (Roche Diagnostics, Laval, QC, Canada). Diagnostic DNA amplifications were performed using polymerase chain reaction (AmpliTaq Gold polymerase; Applied Biosystems, Carlsbad, CA). The primer sequences can be found in Supplemental Table 1.

\section{Gene Expression Analysis of Mouse Tissues}

Tissues from WT and OATP2B1 KO mice were harvested after isoflurane overdose and RNA was extracted using TRIzol (Life Technologies). For small intestine, mucosal samples were collected while whole organ was processed for liver, kidney, brain, and lung. Complementary DNA was obtained by reverse transcription (Multiscribe; Applied Biosystems) with random hexamers. Relative mRNA expression of transporter genes was determined by SYBR Green-based quantitative polymerase chain reaction (7500 system; Applied Biosystems) with normalization to $18 \mathrm{~S}$ ribosomal RNA by TaqMan reagents (Applied Biosystems). The primer sequences can be found in Supplemental Table 2.

\section{Fexofenadine Pharmacokinetics in WT and OATP2B1 KO Mice}

Male (adult, age-matched, 10-31 weeks old) WT and KO mice were used. For intravenous pharmacokinetic studies, fexofenadine $(1 \mathrm{mg} / \mathrm{kg})$ was dissolved in saline and administered via tail vein. Serial blood samples $(\sim 20 \mu \mathrm{l}$ each) from each mouse were collected from the saphenous vein at 5,15 , and 30 minutes and 1 and 2 hours post drug administration in heparinized microcentrifuge tubes. For oral drug administration, animals were fasted for 4 hours prior to drug administration. Fexofenadine $(1 \mathrm{mg} / \mathrm{kg}$ ) dissolved in $200 \mu \mathrm{l}$ of either PBS (pH 3.5 , which is equivalent to GFJ and AJ vehicles, $290 \mathrm{mOsm} / \mathrm{kg}$ ), $4 \times$ concentrated GFJ $(2464 \mathrm{mOsm} / \mathrm{kg})$, or $4 \times$ concentrated AJ $(2794 \mathrm{mOsm} / \mathrm{kg})$, was administered by oral gavage. Serial blood samples $(\sim 20 \mu \mathrm{l}$ each) were obtained from each mouse via the saphenous vein at 5,15 , and 30 minutes and 1,2 , and 3 hours post drug administration in heparinized microcentrifuge tubes. Blood samples were centrifuged at $5000 \mathrm{~g}$ for 10 minutes at $4^{\circ} \mathrm{C}$. Resulting plasma was stored at $-80^{\circ} \mathrm{C}$ until fexofenadine was measured by LC-MS/MS. This animal study protocol was approved by the Animal Use Subcommittee of the University of Western Ontario.

\section{Rosuvastatin Pharmacokinetics in WT and OATP2B1 KO Mice}

Male WT and KO mice between 8 and 16 weeks of age were used for the experiments. Animals were administered $1 \mathrm{mg} / \mathrm{kg}$ rosuvastatin in saline $(<2 \%$ dimethylsulfoxide) by tail vein injection or $10 \mathrm{mg} / \mathrm{kg}$ rosuvastatin by oral gavage in $0.5 \%$ hydroxypropylmethylcellulose. All blood samples ( $\sim 20 \mu \mathrm{l}$ each) were collected by serial sampling from each mouse at 10,20, and 30 minutes and 1,2,4, and 8 hours after oral dosing and 5, 15, and 30 minutes and 1, 2, 4, and 6 hours following intravenous dosing. Blood was collected with a heparinized pipet after saphenous or tail vein puncture and centrifuged at $12,000 \mathrm{~g}$ for 5 minutes to obtain plasma. All plasma and tissue samples were stored at $-80^{\circ} \mathrm{C}$ until analysis by LC-MS/MS. The study protocol was approved by the Animal Use Subcommittee of the University of Western Ontario.

\section{Liquid Chromatography-Tandem Mass Spectrometry}

Fexofenadine Assay. Plasma samples $(5 \mu \mathrm{l})$ were spiked with internal standard (d6-fexofenadine, $5 \mu \mathrm{l}, 200 \mathrm{ng} / \mathrm{ml}$ ), precipitated with acetonitrile $(15 \mu \mathrm{l})$ 
and centrifuged for 10 minutes at 13,500 rpm. The resulting supernatant $(20 \mu \mathrm{l})$ was diluted with $125 \mu \mathrm{l}$ of $0.1 \%$ formic acid in water (v/v). Standard curve samples were created by spiking fexofenadine into blank human ethylenediaminetetraacetic acid plasma (Bioreclamation IVT, Baltimore, MD) for subsequent processing similar to plasma samples. Analytes were separated by liquid chromatography (Agilent 1200; Agilent, San Clara, CA) using a Hypersil Gold C18 column $(50 \times$ $3 \mathrm{~mm}, 5 \mu \mathrm{m}$; Thermo Fisher Scientific) following sample injection (75 $\mu \mathrm{l}$ for plasma samples). A mobile phase of $0.1 \% \mathrm{v} / \mathrm{v}$ formic acid in water (A) and acetonitrile (B) was used, with an elution gradient of $20 \%$ B from 0 to 1 minute, $20 \%-95 \%$ B from 1.0 to 4.5 minutes, $95 \%$ B from 4.50 to 5.25 minutes, $95 \%-20 \%$ B from 5.25 to 5.80 minutes, and $20 \%$ B from 5.8 to 6.0 minutes, for a run time of 6 minutes and flow rate of $0.5 \mathrm{ml} / \mathrm{min}$. The heated electrospray ionization source of the triple quadrupole mass spectrometer (Thermo TSQ Vantage; Thermo Fisher Scientific) was operated in positive mode $\left(3500 \mathrm{~V}, 350^{\circ} \mathrm{C}\right)$ with collision energy set at $25 \mathrm{~V}$. Additional ionization source conditions used were as follows: 40 arbitrary units for sheath gas pressure, 15 arbitrary units for auxiliary gas pressure, and $350^{\circ} \mathrm{C}$ for capillary temperature. Selected reaction monitoring for fexofenadine and d6-fexofenadine was performed using mass-to-charge ratio $(\mathrm{m} / \mathrm{z})$ transitions $502.2 \rightarrow 466.5 \mathrm{~m} / \mathrm{z}$ and $508.2 \rightarrow 472.5 \mathrm{~m} / \mathrm{z}$, respectively. Both solutes had chromatographic retention time of 3.2 minutes. Calibration curves were linear with plasma fexofenadine concentrations between 0 and $3000 \mathrm{ng} / \mu \mathrm{l}$. Interday assay accuracy and precision were $3.2 \%$ and $10.0 \%$, respectively. The lower limit of quantitation was $2 \mathrm{ng} / \mathrm{ml}$.

Rosuvastatin Assay. The concentration of rosuvastatin in plasma was determined as previously reported (DeGorter et al., 2012). Briefly, plasma samples were precipitated with acetonitrile containing d6-rosuvastatin as an internal standard and centrifuged for 20 minutes at $14,000 \mathrm{rpm}$ at $4^{\circ} \mathrm{C}$. The supernatant was diluted $1: 2$ in $0.05 \%$ formic acid and analyzed by LC-MS/MS Solutes were separated by reverse-phase chromatography on a Hypersil GOLD C18 column $(50 \times 3 \mathrm{~mm}, 5 \mu \mathrm{m}$; ThermoFisher Scientific) with $0.05 \%$ formic acid/water and acetonitrile solvent gradient. After electrospray ionization, mass spectrometric detection (TSQ Vantage) was performed in positive mode with transitions $482.1 \rightarrow 258.2 \mathrm{~m} / \mathrm{z}$ for rosuvastatin and $488.0 \rightarrow 264.3 \mathrm{~m} / \mathrm{z}$ for d6-rosuvastatin. Calibration curves were linear with plasma rosuvastatin concentrations between 0 and $1000 \mathrm{ng} / \mu \mathrm{l}$, while interday assay accuracy and precision were $5.8 \%$ and $8.9 \%$, respectively. The lower limit of quantitation was $1 \mathrm{ng} / \mathrm{ml}$.

\section{Pharmacokinetic Calculations}

Pharmacokinetic analysis was performed using noncompartmental methods. The area under the concentration-time curve from time zero to the last sampling time $\left(\mathrm{AUC}_{0-\text { last }}\right)$ was calculated using the linear trapezoid method. The area under the concentration-time curve from time zero to infinity $\left(\mathrm{AUC}_{0-\infty}\right)$ was calculated as the sum of $\mathrm{AUC}_{0-\text { last }}$ and $C_{\text {last }} / k$, where $C_{\text {last }}$ is the last sampled concentration and $k$ is the elimination rate constant obtained from the regressed slope of $1 n$-transformed terminal concentrations. The terminal half-life $\left(t_{1 / 2}\right)$ was determined from $\ln 2 / k$. The maximal plasma concentration $\left(C_{\max }\right)$ and the time to maximum plasma concentration $\left(T_{\max }\right)$ values were obtained directly from the observed results. Plasma clearance $\left(\mathrm{CL}_{\text {plasma }}\right)$ was calculated as intravenous dose divided by $\mathrm{AUC}_{0-\infty}$. Mean residence time was calculated as the area under the first moment $(C \times t)$ curve divided by $\mathrm{AUC}_{0-\infty}$. The volume of distribution at steady state was calculated as the product of the mean residence time and $\mathrm{CL}_{\text {plasma }}$. Bioavailability was calculated as $\mathrm{AUC}_{0-\infty, \text { oral }} / \mathrm{AUC}_{0-\infty, \text { intravenous }} \times$ Dose $_{\text {intravenous }} /$ Dose $_{\text {oral }}$.

\section{Statistics}

The unpaired two-tailed Student's $t$ test was used to determine statistical differences between groups. Statistical significance was deemed at $P<$ 0.05. All statistical analyses were conducted using GraphPad Prism (La Jolla, CA).

\section{Results}

Mouse OATP2B1 Transport Activity toward Prototypical Substrates. An MDCKII cell line stably expressing mOATP2B1 was developed to characterize solute transport activity. Immunofluorescence imaging demonstrated that mOATP2B1 was localized largely on the plasma membrane of MDCKII-mOATP2B1 cells grown as a monolayer on plastic dishes (Fig. 1A), while immunoblot analysis confirmed heterologous expression of mOATP2B1 (Fig. 1B). Next, the uptake of previously reported human OATP2B1 substrates, estrone sulfate (Tamai et al., 2000), dehydroepiandrosterone sulfate (Kullak-Ublick et al., 2001), and bromosulfophthalein (Kullak-Ublick et al., 2001), was evaluated in the MDCKII-mOATP2B1 cell line. In comparison with the MDCKII-control cells, estrone sulfate, dehydroepiandrosterone sulfate, and bromosulfophthalein uptake values were 2.8-, 1.8-, and 3.5-fold greater in the MDCKII-mOATP2B1 cells (Fig. 1C), respectively. The bile acid taurocholate has been reported to be a substrate of human OATP2B1 in some studies (Nozawa et al., 2004), but not others (Kullak-Ublick et al., 2001; Knauer et al., 2013). We found that taurocholate uptake was 2.5-fold greater in MDCKII cells expressing mOATP2B1 compared with control cells (Fig. 1C), indicating that mOATP2B 1 is a bile acid transporter. These results demonstrate that mouse and human OATP2B1 have generally similar substrate specificities.

Fexofenadine Transport by Mouse OATP2B1. Fexofenadine was found to be a human OATP2B1 substrate in studies with transfected HEK293 (Nozawa et al., 2004) and MDCKII cells (Ming et al., 2011) and in the Xenopus laevis oocyte model (Shirasaka et al., 2014), but not by others using OATP2B1-expressing HEK293 (Shimizu et al., 2005) or HeLa (Glaeser et al., 2007) cells. In previous studies with fexofenadine, acidic extracellular $\mathrm{pH}$ enhanced OATP2B1-mediated cellular uptake (Nozawa et al., 2004); therefore, we performed experiments for mOATP2B 1 in uptake media adjusted to $\mathrm{pH} 6$. We observed that $\left[{ }^{3} \mathrm{H}\right]$ fexofenadine uptake was 1.25 -fold greater in HeLa cells transiently transfected with mOATP2B1 compared with vector control-transfected cells (Fig. 1D). Furthermore, unlabeled fexofenadine accumulated at 1.8-fold higher levels in the MDCKII-mOATP2B1 cell line compared with MDCKII-control cells (Fig. 1D). Concentration dependency for fexofenadine uptake (0.1-300 $\mu \mathrm{M})$ was studied in MDCKII-control and MDCKII-mOATP2B1 cells. The mOATP2B1-mediated fexofenadine uptake appeared concentration dependent, with loss of linearity more evident at the highest concentration examined (Fig. 1E). Evaluation of kinetics by Eadie-Hofstee plot analysis (V/S vs. V) (Fig. 1E) did not expose multiple binding sites for mOATP2B1 that were previously observed for fexofenadine and human OATP2B1 (Shirasaka et al., 2014). Solubility precluded the ability to study higher fexofenadine concentrations than $300 \mu \mathrm{M}$, and hence we were not able to estimate kinetic parameters $K_{\mathrm{M}}$ and $V_{\max }$. Finally, we found that mOATP2B1mediated cellular bromosulfophthalein uptake in the MDCKII model was inhibited by $57 \%$ in the presence of the known potent human OATP2B1 inhibitor/substrate, erlotinib $(10 \mu \mathrm{M})$ (Johnston et al., 2014; Bauer et al., 2018) and by $33 \%$ with fexofenadine $(300 \mu \mathrm{M})$ (Fig. 1F). Taken together, these results show that fexofenadine is a substrate for mOATP2B1.

Rosuvastatin Transport by Mouse OATP2B1. Human OATP2B1, including both its major intestinal and hepatic protein variants, has been shown to transport rosuvastatin (Ho et al., 2006; Knauer et al., 2013). Using two different cell expression models we examined whether mOATP2B 1 also transports rosuvastatin. Rosuvastatin uptake was increased 2.1- and 18.9-fold in HeLa cells transiently transfected with mOATP2B1 and MDCKII-mOATP2B1 cells, respectively, when compared with experimental control cells (Fig. 1G). Thus, rosuvastatin is a substrate of $\mathrm{mOATP} 2 \mathrm{~B} 1$.

Characterization of Mice with Targeted Disruption of mOATP2B1. In collaboration with the Knockout Mouse Consortium (KOMP), we developed a mouse model with targeted disruption of mOATP2B1 by introduction of a gene trap cassette within the Slco2bl 
A

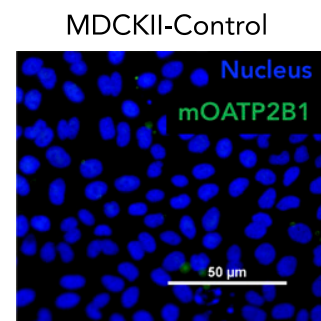

MDCKII-mOATP2B1

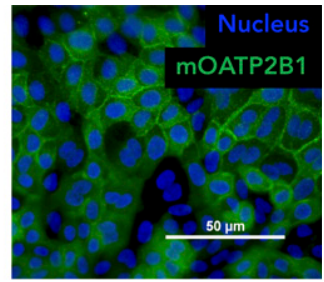

B

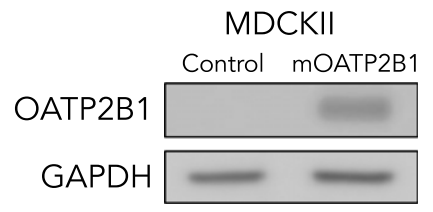

C

Estrone Sulfate

DHEAS

Bromosulfophthalein

Taurocholate
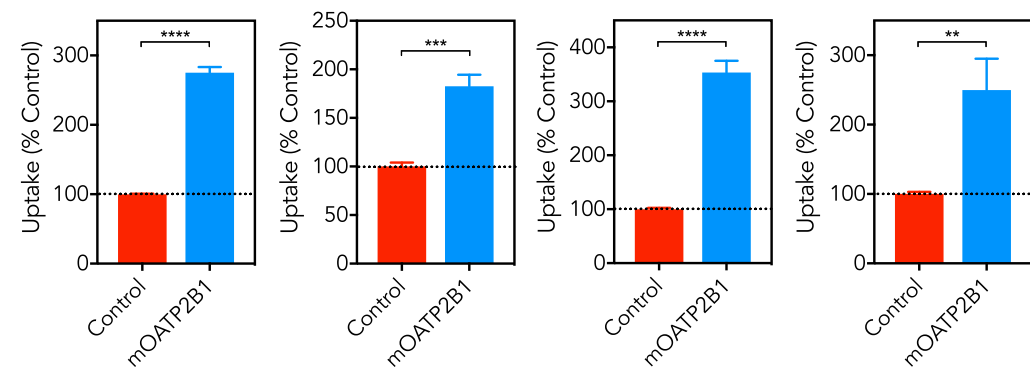

D

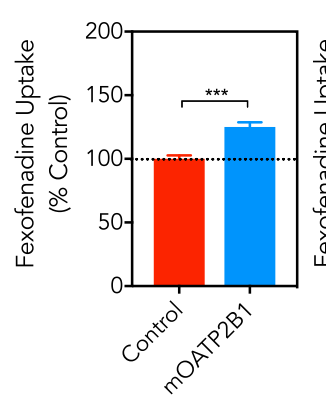

F

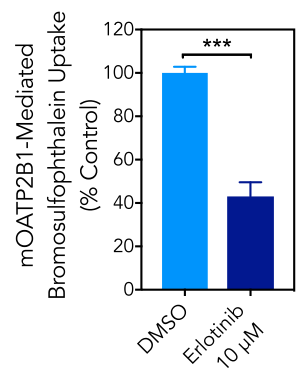

MDCKII
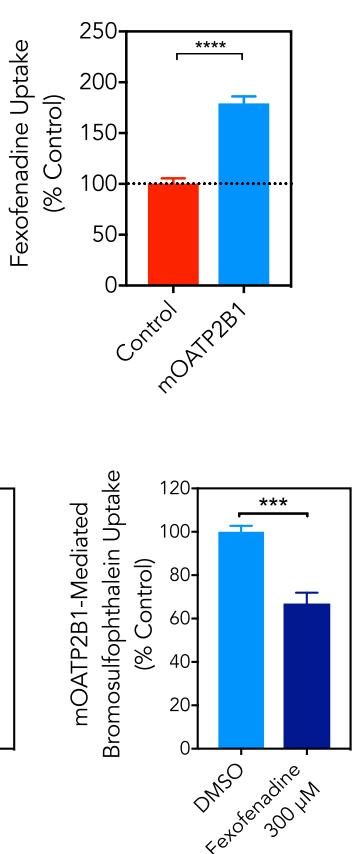

E

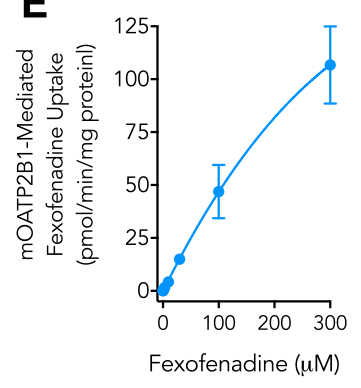

G

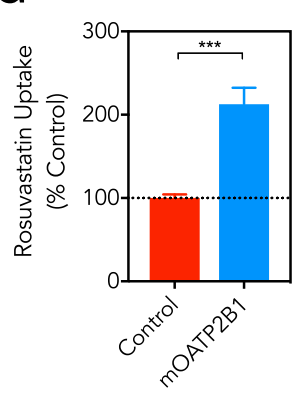

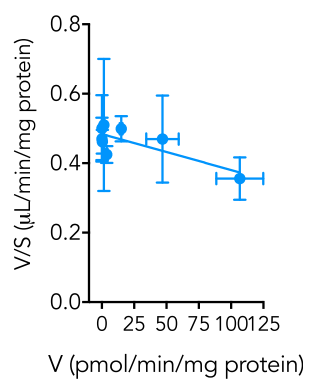

MDCKII

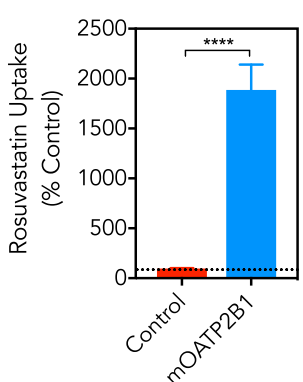

Fig. 1. Characterization of solute transport by mOATP2B1. (A) Expression and localization of mOATP2B1 (green) in MDCKII-control and MDCKII-mOATP2B1 cells after stable transfection by immunofluorescence microscopy. Nuclei are stained with 4',6-diamidino-2-phenylindole (blue). (B) Immunoblot analysis of mOATP2B1 expression in MDCKII-control and MDCKII-mOATP2B1 cells. Glyceraldehyde-3-phosphate dehydrogenase (GAPDH) was used as the protein loading control. (C) Cellular accumulation of $\left[{ }^{3} \mathrm{H}\right]$-estrone sulfate $(5 \mathrm{nM}, N=3)$, dehydroepiandrosterone sulfate (DHEAS) $\left.(1 \mu \mathrm{g} / \mathrm{ml}, N=3),{ }^{3} \mathrm{H}\right]$-bromosulfophthalein $(5 \mathrm{nM}, N=4)$, and taurocholate $(2 \mu \mathrm{g} / \mathrm{ml}, N=3)$ in MDCKII-control and MDCKII-mOATP2B1 after 10-minute incubation with compounds in Krebs-Henseleit buffer (KHB) at pH 6. Cellular uptake was corrected for protein content per well and normalized to MDCKII-control (\% control). (D) Cellular uptake of fexofenadine in HeLa cells transiently transfected with mock empty vector/mOATP2B1 or MDCKII-control/MDCKII-mOATP2B1 cells. For HeLa experiments $\left[{ }^{3} \mathrm{H}\right]$-fexofenadine $(0.1 \mu \mathrm{M}, N=6)$ was applied, while for MDCKII studies unlabeled fexofenadine $(0.1 \mu \mathrm{M}, N=5)$ was applied to cells dissolved in KHB pH 6 for 30 or 10 minutes, respectively. For MDCKII cell experiments, cellular uptake was corrected for protein content per well and normalized to MDCKII-control (\% control). (E) Concentration-dependent fexofenadine uptake by mOATP2B1. Unlabeled fexofenadine (0.1-300 $\mu \mathrm{M})$ dissolved in KHB at pH 6 was applied to MDCKII-control and MDCKII-mOATP2B1 cells for 10 minutes. The mOATP2B1-mediated uptake was calculated as the difference between uptake of mOATP2B1 and control cells with correction of protein content per well. Eadie-Hofstee (V/S vs. V) plot with the line obtained by linear regression (V/S $=-0.001037 \mathrm{~V}+0.4842, P=0.025)$. (F) Inhibition of mOATP2B1 activity by erlotinib and fexofenadine. MDCKII-control and MDCKIImOATP2B1 cells were incubated with $\left[{ }^{3} \mathrm{H}\right]$-bromosulfophthalein $(5 \mathrm{nM}, N=3)$ and erlotinib $(10 \mu \mathrm{M})$, fexofenadine $(300 \mu \mathrm{M})$, or vehicle for 10 minutes in $\mathrm{KHB}$ at pH 6 . Cellular drug accumulation was corrected for protein content. The mOATP2B1-specific uptake was calculated as the difference between MDCKII-mOATP2B1 and MDCKII-control cells and normalized to MDCKII-control (\% control). (G) Cellular uptake of rosuvastatin in HeLa cells transiently transfected with mOATP2B1 or MDCKII-control/MDCKII-mOATP2B1 cells. For HeLa experiments $\left[{ }^{3} \mathrm{H}\right]$-rosuvastatin $(0.1 \mu \mathrm{M}, N=3)$ was applied to cells dissolved in Opti-MEM media, while for MDCKII studies unlabeled rosuvastatin $(0.1 \mu \mathrm{M}, N=5)$ was dissolved in KHB pH 6 for 30 or 10 minutes, respectively. For MDCKII cell experiments, cellular uptake was corrected for protein content per well and normalized to MDCKII-control (\% control). Results are shown as mean \pm S.E.M. $* * P<0.01 ; * * * P<0.001 ; * * * * P<0.0001$ as determined by unpaired, two-tailed Student's $t$ test. 
locus. These KO mice were viable at birth, fertile, produced litters of normal size, and appeared to have a normal life span. No differences have been observed in the weight or growth rate of $\mathrm{KO}$ mice compared with WT animals. Organs and tissues were normal in KO mice after macroscopic examination and histologic analyses. Serum biochemistries of the $\mathrm{KO}$ mice were unremarkable. In adult male $\mathrm{KO}$ mice, we observed an absence of mOATP2B1 mRNA in tissues that highly express the transporter in WT mice, namely, liver, kidney, small intestine, brain, and lung (Fig. 2A). In WT mice, the expression of mOATP2B1 was greatest in liver but undetectable in $\mathrm{KO}$ mice by immunofluorescence microscopy (Fig. 2B) and western blot (Fig. 2C). We next compared the expression of potential fexofenadine and rosuvastatin transporters in the small intestine, liver, and kidney of WT and KO mice to understand whether there was compensation for loss of mOATP2B1 expression. Uptake transporter expressions of mOATP1A1, mOATP1A4, mOATP1A5, mOATP1A6, mOATP1B2, and mOCT1 mRNAs were not different among WT and KO mice in these tissues (Fig. 2D). Moreover, the mRNA expression of efflux transporters including Mrp2, Mdr1a, and Bcrp were not different in the KO mice (Fig. 2D). Taken together, we confirm successful targeted global disruption of mOATP2B1 in the $\mathrm{KO}$ mouse model and report a lack of compensation of gene expression by other transporters that may be relevant to fexofenadine and rosuvastatin disposition.

Fexofenadine Pharmacokinetics in Mice with Targeted Disruption of OATP2B1. The plasma pharmacokinetic effects of fexofenadine were determined in adult male WT and KO mice after intravenous $(1 \mathrm{mg} / \mathrm{kg})$ and oral $(1 \mathrm{mg} / \mathrm{kg})$ administration. With intravenous administration, there was a lack of difference in the plasma concentrations of fexofenadine between WT and KO mice (Fig. 3A). Pharmacokinetic analyses showed the fexofenadine $\mathrm{CL}_{\text {plasma }}$, volume of distribution at steady state, and $t_{1 / 2}$ were similar among WT and KO mice (Table 1). Next, fexofenadine was administered orally to WT and $\mathrm{KO}$ in PBS-vehicle at $\mathrm{pH}$ 3.5, a $\mathrm{pH}$ value similar to that measured in GFJ and AJ. We found fexofenadine plasma concentrations were lower in $\mathrm{KO}$ compared with WT mice with oral administration (Fig. 3B). In $\mathrm{KO}$ mice, $C_{\max }$ and $\mathrm{AUC}_{0 \text {-last }}$ were lower by $70 \%$ and $41 \%$, respectively in comparison with WT mice
(Table 1). No differences in either $T_{\max }$ or $t_{1 / 2}$ among WT and KO groups were observed. It should be noted that the estimates for $t_{1 / 2}$ were less reliable due to the limited sampling duration. The estimated bioavailability was lower in KO versus WT mice (3.9\% vs. $5.2 \%$, respectively), but not statistically significant. However, the values for $\mathrm{AUC}_{0-\infty}$, which were used to estimate bioavailability, were not particularly adequate given that the sampling duration may not have been sufficient. These results demonstrate that mOATP2B1 significantly affects the pharmacokinetics of oral but not intravenous fexofenadine. That fexofenadine remained absorbed in $\mathrm{KO}$ mice after oral administration, albeit at a significantly lower degree than in WT mice, indicates transporters aside from mOATP2B1 may also be responsible for fexofenadine absorption.

Impact of Fruit Juice Coadministration on Fexofenadine Oral Pharmacokinetics in WT and KO Mice. The effects of coadministered GFJ or AJ on fexofenadine pharmacokinetics in WT and $\mathrm{KO}$ were evaluated. In WT mice, GFJ reduced fexofenadine plasma concentrations (Fig. 3C), with significant reductions in $C_{\max }$ and $\mathrm{AUC}_{0-\text { last }}$ by $80 \%$ and $35 \%$, respectively (Table 1 ). GFJ increased oral fexofenadine $T_{\max }$ in WT mice (Table 1). Oral AJ coadministration had greater effect than GFJ on fexofenadine plasma concentrations in WT mice (Fig. 3C) with lower $C_{\max }$ and $\mathrm{AUC}_{0 \text {-last }}$ values of $88 \%$ and $70 \%$, respectively, in comparison with vehicle control (Table 1). These results demonstrate that mice can recapitulate the fruit juice effect on oral fexofenadine pharmacokinetics observed originally in humans (Dresser et al., 2002). In $\mathrm{KO}$ mice, GFJ coadministration did not further reduce plasma fexofenadine concentrations (Fig. 3D) or alter pharmacokinetic parameters when compared with vehicle control. However, in $\mathrm{KO}$ mice AJ coadministration significantly reduced both fexofenadine $C_{\max }$ and $\mathrm{AUC}_{0-\text { last }}$ values by $67 \%$ and $59 \%$, respectively, when compared with vehicle control (Table 1). Taken together, these findings suggest that mOATP2B1 is largely responsible for altered oral fexofenadine pharmacokinetics with GFJ coadministration. Given that AJ sustained additional reductions in systemic fexofenadine exposure in $\mathrm{KO}$ mice, this indicates that the AJ effect on oral fexofenadine pharmacokinetics in WT mice is dependent on both mOATP2B1 and other transporters.
A
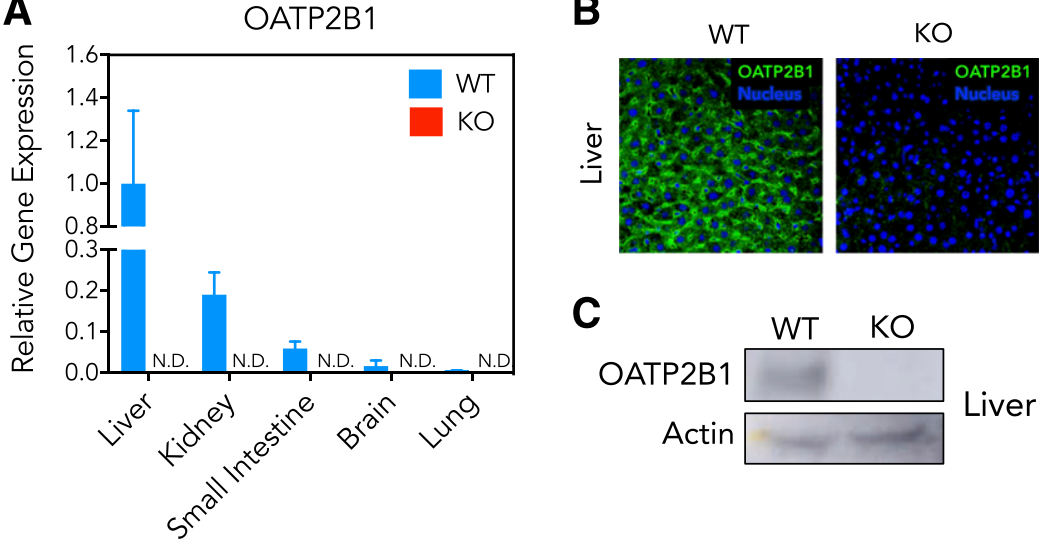

C

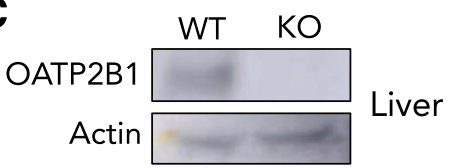

D
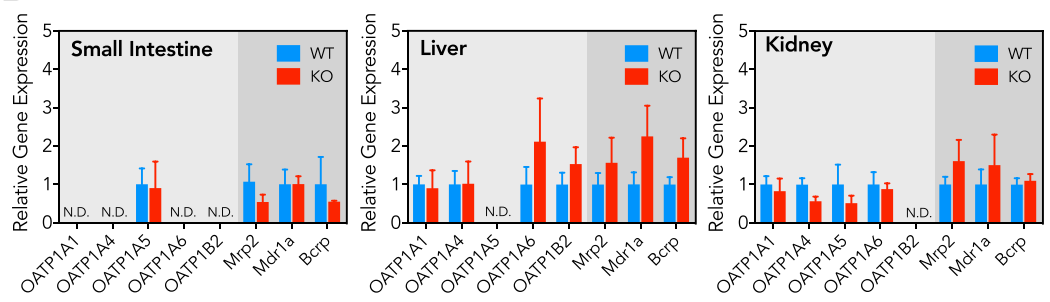

Fig. 2. Tissue gene expression in mOATP2B1 KO mice. (A) Liver, kidney, small intestine mucosa, brain, and lung from adult male WT and KO $(N=3-5)$ mice were harvested for OATP2B1 mRNA expression by reverse-transcription quantitative polymerase chain reaction (PCR). 18S RNA served as the gene normalization control. Relative gene expression is presented in relation to liver using the $\Delta \Delta \mathrm{Ct}$ method. (B) Expression and localization of mOATP2B1 (green) in WT and KO mouse liver by immunofluorescence microscopy. Nuclei are stained with 4',6-diamidino-2-phenylindole (blue). (C) Immunoblot analysis of mOATP2B1 expression in WT and KO mouse liver. Actin was used as the protein loading control. (D) Drug transporter mRNA gene expression in small intestine, liver, and kidney as determined by reverse-transcription quantitative PCR. 18S RNA served as the gene normalization control. Relative gene expression is presented in relation to each transporter for WT mice using the $\Delta \Delta \mathrm{Ct}$ method. Results are shown as mean \pm S.E.M. N.D., not detected. 
A

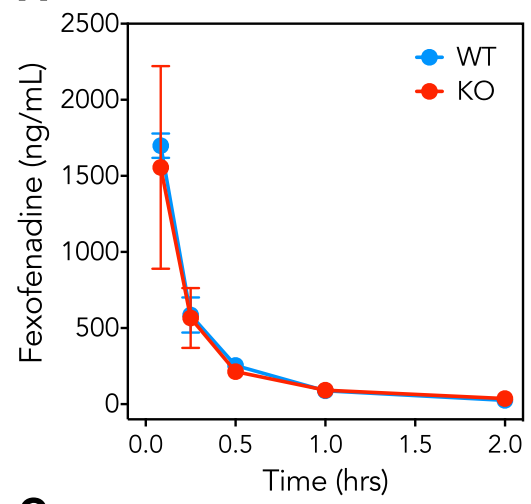

C

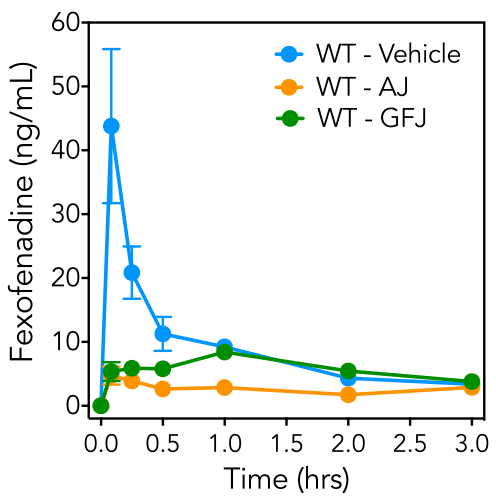

B

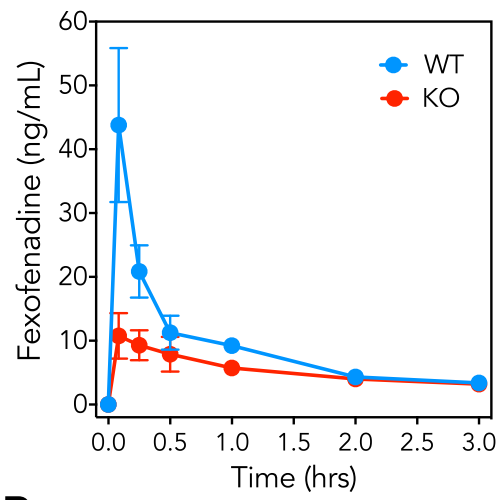

D

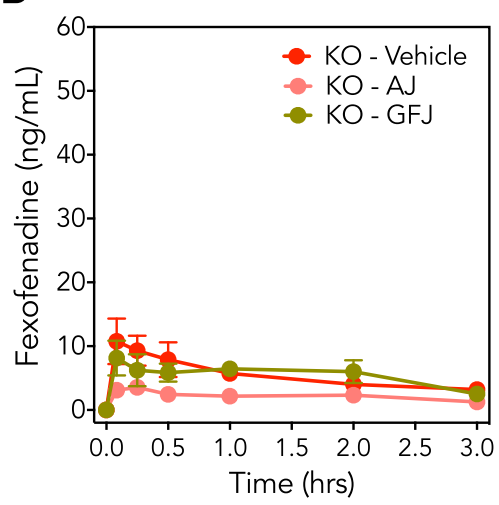

Fig. 3. Fexofenadine pharmacokinetics. (A) Fexofenadine (1 mg/kg in saline) was administered by intravenous bolus injection to adult male WT $(N=4)$ and $\mathrm{KO}(N=5)$ mice. (B) Adult male WT $(N=17)$ and $\mathrm{KO}(N=14)$ mice were administered fexofenadine by oral gavage [1 mg/kg in $200 \mu \mathrm{l}$ PBS (pH 3.5)]. (C) Adult male WT mice were administered fexofenadine $(1 \mathrm{mg} / \mathrm{kg})$ by oral gavage in either $200 \mu \mathrm{l}$ PBS at pH $3.5(N=17), 200 \mu \mathrm{l} 4 \times$ concentrated GFJ $(N=8)$, or $200 \mu \mathrm{l} 4 \times$ concentrated AJ $(N=9)$. (D) Adult male KO mice were administered fexofenadine $(1 \mathrm{mg} / \mathrm{kg})$ by oral gavage in either $200 \mu \mathrm{l}$ PBS at pH $3.5(N=14), 200 \mu \mathrm{l} 4 \times$ concentrated GFJ $(N=7)$, or $200 \mu \mathrm{l} 4 \times$ concentrated AJ $(N=9)$. Plasma was obtained at various time intervals by saphenous venous sampling and fexofenadine concentrations were determined by LC-MS/MS. Plasma concentrations are shown as mean \pm S.E.M.
Identification of Other Mouse Uptake Transporters for Fexofenadine. We explored whether other transporters mediate fexofenadine uptake as an explanation for the in vivo pharmacokinetic findings. Indeed, previous studies demonstrate that rat OATP (rOATP) 1A1, rOAT1A4, rOATP1A5, and rOATP1B2 transport fexofenadine (Cvetkovic et al., 1999; Dresser et al., 2002; Glaeser et al., 2007). Upon heterologous expression of mouse OATP transporters in cultured cells, we found that fexofenadine was a substrate of mOATP1A1, mOATP1A4, and mOATP1A5, but not mOATP1A6 (Fig. 4A). Human OCT1 was previously shown to transport fexofenadine (Glaeser et al., 2007), while OCT3 and plasma membrane monoamine transporters are cation uptake transporters expressed in enterocytes (Kekuda et al., 1998; Zhou et al.,
2007). Moreover, in vitro studies showed that plasma membrane monoamine transporter-mediated atenolol transport is inhibited by $\mathrm{AJ}$ flavonoids (Mimura et al., 2017). Here, we found that mOCT1 transports fexofenadine but this was not evident for mOCT3 or mPMAT (Fig. 4B). Since only mOATP1A5 and mOCT1 are expressed in the small intestine (Fig. 2D), it is possible that these transporters may also be involved in the oral absorption of fexofenadine in mice.

Rosuvastatin Pharmacokinetics in Mice with Targeted Disruption of OATP2B1. With intravenous $(1 \mathrm{mg} / \mathrm{kg}$ ) (Fig. 5A) and oral administration $(10 \mathrm{mg} / \mathrm{kg}$ ) (Fig. 5B) of rosuvastatin, there were no significant differences in the plasma concentrations of rosuvastatin between WT and KO mice. A lack of differences in the $\mathrm{CL}_{\text {plasma }}$ and

TABLE 1

Fexofenadine pharmacokinetic parameters

\begin{tabular}{|c|c|c|c|c|c|c|c|c|}
\hline \multirow{2}{*}{$\begin{array}{l}\text { Pharmacokinetic } \\
\text { Parameter }\end{array}$} & \multicolumn{4}{|c|}{ WT Mice (1 mg/kg Fexofenadine) } & \multicolumn{4}{|c|}{ KO Mice (1 mg/kg Fexofenadine) } \\
\hline & $\begin{array}{l}\text { Intravenous Dose } \\
\quad(N=4)\end{array}$ & $\begin{array}{l}\text { Oral Dose [PBS- } \\
\text { Vehicle }(N=17)]\end{array}$ & $\begin{array}{l}\text { Oral Dose [GFJ } \\
\quad(N=8)]\end{array}$ & $\begin{array}{l}\text { Oral Dose [AJ } \\
\quad(N=9)]\end{array}$ & $\begin{array}{l}\text { Intravenous Dose } \\
\quad(N=5)\end{array}$ & $\begin{array}{l}\text { Oral Dose [PBS- } \\
\text { Vehicle }(N=14)]\end{array}$ & $\begin{array}{l}\text { Oral Dose [GFJ } \\
\qquad(N=7)]\end{array}$ & $\begin{array}{l}\text { Oral Dose [AJ } \\
\quad(N=9)]\end{array}$ \\
\hline$C_{0}(\mathrm{ng} / \mathrm{ml})$ & $3000 \pm 630$ & - & - & - & $2620 \pm 2720$ & - & - & - \\
\hline$C_{\max }(\mathrm{ng} / \mathrm{ml})$ & - & $46.0 \pm 48.3$ & $9.3 \pm 3.9^{a}$ & $5.6 \pm 3.6^{a}$ & - & $14.5 \pm 14.9^{b}$ & $11.9 \pm 6.7$ & $4.7 \pm 2.5^{c}$ \\
\hline$T_{\max }(\mathrm{h})$ & - & $0.25 \pm 0.36$ & $0.82 \pm 0.34^{a}$ & $0.64 \pm 0.93$ & - & $0.32 \pm 0.27$ & $0.64 \pm 0.73$ & $0.84 \pm 0.73$ \\
\hline $\begin{array}{l}\mathrm{AUC}_{0-\text { last }}(\mathrm{ng} / \mathrm{ml} \times \\
\mathrm{h})\end{array}$ & $634 \pm 79$ & $27.2 \pm 14.4$ & $17.7 \pm 8.2^{a}$ & $8.1 \pm 3.8^{a}$ & $590 \pm 424$ & $16.1 \pm 11.2^{b}$ & $16.5 \pm 9.0$ & $6.6 \pm 2.9^{c}$ \\
\hline $\mathrm{AUC}_{0-\infty}(\mathrm{ng} / \mathrm{ml} \times \mathrm{h})$ & $652 \pm 83$ & $33.6 \pm 15.8$ & $32.9 \pm 12.3$ & $13.8 \pm 7.6^{a}$ & $623 \pm 425$ & $24.1 \pm 12.6$ & $22.7 \pm 12.5$ & $7.7 \pm 1.8^{c}$ \\
\hline MRT (h) & $0.36 \pm 0.09$ & $1.9 \pm 1.8$ & $4.2 \pm 3.7$ & $3.3 \pm 1.1^{a}$ & $0.53 \pm 0.16$ & $2.8 \pm 1.5$ & $3.3 \pm 1.8$ & $2.4 \pm 1.2$ \\
\hline$t_{1 / 2}(\mathrm{~h})$ & $0.48 \pm 0.10$ & $1.7 \pm 1.7$ & $2.7 \pm 2.6$ & $2.2 \pm 0.7$ & $0.62 \pm 0.06$ & $1.8 \pm 1.1$ & $2.2 \pm 1.4$ & $1.5 \pm 0.8$ \\
\hline$V_{\mathrm{ss}}(\mathrm{ml} / \mathrm{kg})$ & $553 \pm 121$ & - & - & - & $1151 \pm 542$ & - & - & - \\
\hline $\begin{array}{l}\mathrm{CL}_{\text {plasma }}(\mathrm{ml} / \mathrm{min} \text { per } \\
\text { kilogram })\end{array}$ & $25.9 \pm 3.3$ & - & - & - & $33.9 \pm 13.8$ & - & - & - \\
\hline$F(\%)$ & - & $5.2 \pm 2.4$ & $5.0 \pm 1.9$ & $2.1 \pm 1.2^{a}$ & - & $3.9 \pm 2.0$ & $3.7 \pm 2.0$ & $1.2 \pm 0.3^{c}$ \\
\hline
\end{tabular}

$F$, bioavailability; MRT, mean residence time; $V_{\mathrm{ss}}$, volume of distribution at steady state.

${ }^{a} P<0.05$ compared with WT $[1 \mathrm{mg} / \mathrm{kg}$, orally (PBS-vehicle)].

${ }^{b} P<0.05$ compared with WT $[1 \mathrm{mg} / \mathrm{kg}$, orally (PBS-vehicle)].

${ }^{c} P<0.05$ compared with KO $[1 \mathrm{mg} / \mathrm{kg}$, orally (PBS-vehicle)].

- , not applicable. 

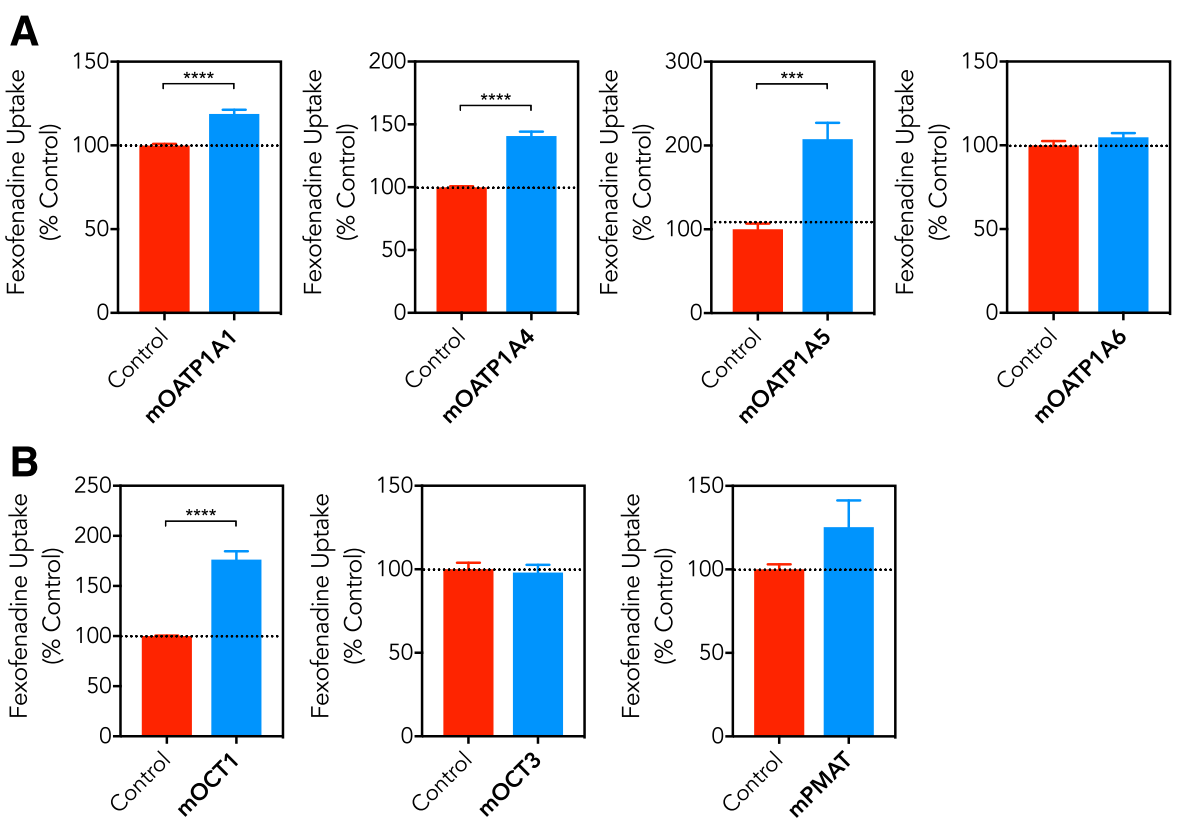

Fig. 4. Fexofenadine transport by mouse transporters. (A) mOATP-mediated transport was determined in HeLa cells transiently transfected with mock empty vector, mOATP1A1 $(N=7)$, mOATP1A4 $(N=7)$, or mOATP1A6 $(N=3)$. For other transporters, HEK293T cells were transiently transfected with mock vector control or mOATP1A5 $(N=3)$. (B) Organic cation transporter-mediated transport of fexofenadine was evaluated in HeLa cells transiently transfected with mock empty vector, mOCT1 $(N=4)$ or mOCT3 $(N=4)$. In other experiments MDCKII-control and MDCKII-mPMAT stable cells $(N=3)$ were used. $\left[{ }^{3} \mathrm{H}\right]$-fexofenadine $(0.1 \mu \mathrm{M})$ was applied to cells in Krebs-Henseleit buffer at $\mathrm{pH} 6$ (mOATPs) or $\mathrm{pH} 7.5$ for other transporters for 10 minutes and cellular accumulation was determined. For MDCKII cell experiments. Cellular uptake was corrected for protein content per well and normalized to MDCKII-control (\% control). Results are shown as mean \pm S.E.M. $* * * P<0.001, * * * * P<0.0001$ as determined by unpaired, two-tailed Student's $t$ test.

volume of distribution at steady state between WT and KO mice after intravenous administration (Table 2) indicates that the systemic disposition of rosuvastatin is not appreciably affected by OATP2B1. Furthermore, since the bioavailability of rosuvastatin was similar between WT and KO mice ( $8.7 \%$ vs. $11.4 \%$, respectively) (Table 2), this result suggests that OATP2B1 does not significantly contribute to the oral absorption of rosuvastatin in mice.

\section{Discussion}

On the basis of clinical pharmacokinetic fruit juice-drug interactions, OATP2B1 has been implicated as a determinant of oral drug absorption (Tamai and Nakanishi, 2013; Yu et al., 2017; McFeely et al., 2019). Indeed, the International Transporter Consortium considers OATP2B1 as a transporter of emerging clinical importance, although at present it does not recommend prospective testing with OATP2B1 during drug development due to lack of sufficient clinical evidence (ZamekGliszczynski et al., 2018). A compelling case for OATP2B1 is complicated by some examples of in vitro/clinical disconnect, as well as recent reevaluation of the localization of the transporter in enterocytes (Keiser et al., 2017; Oswald, 2019). Moreover, SLCO2B1 pharmacogenetic studies of substrates such as fexofenadine have been conflicting and inconsistent (Akamine et al., 2010; Imanaga et al., 2011). For rosuvastatin, neither the common $S L C O 2 B 1$ c. $935 \mathrm{G}>\mathrm{A}$ nor c. $1457 \mathrm{C}>\mathrm{T}$ genetic polymorphisms have been associated with altered plasma concentrations (DeGorter et al., 2013; Kashihara et al., 2017). Therefore, there is a need for additional studies and strategies to clarify the role of OATP2B1 in drug disposition and response.

We developed a novel whole-body OATP2B1 knockout mouse model to provide essential in vivo insights to connect results from in vitro studies to clinical observations. OATP2B1 is conserved throughout evolution, being found in worms, amphibians, fish, birds, and mammals (Hagenbuch and Stieger, 2013). Importantly, it is the only member of the OATP2B subfamily in all species that greatly simplifies the study of OATP2B1 across different animal models. However, a challenge of studying OATP function in rodents is the complex orthology among the drug-transporting OATP1A/1B transporters. For instance, humans have OATP1A2, while mice and rats express OATP1A1, OATP1A4, OATP1A5, and OATP1A6. Furthermore, there is a single rodent ortholog (OATP1B2) for the human OATP1B1 and OATP1B3. In small intestinal enterocytes, humans express OATP2B1, while rodents have OATP1A5 and OATP2B1. In hepatocytes, humans express OATP1B1, OATP1B3, and OATP2B1, whereas rodents have a larger complement of OATP1A1, OATP1A4, OATP1A6, OATP1B2, and OATP2B1. We have found a lack of difference in OATP1A/1B mRNA expression between WT and KO mice in intestine, liver, and
A

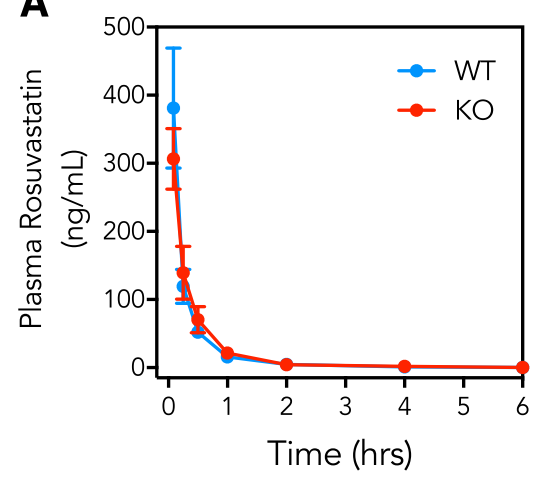

B

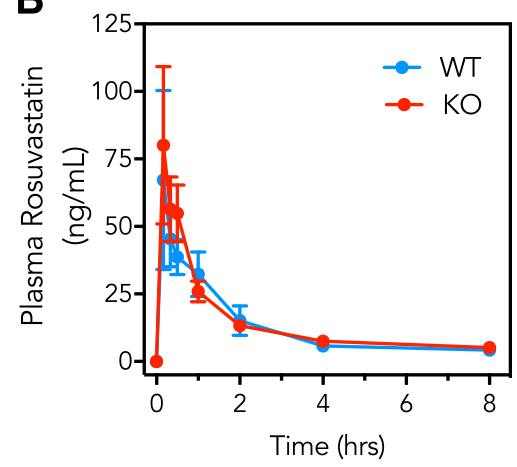

Fig. 5. Rosuvastatin pharmacokinetics. (A) Rosuvastatin $(1 \mathrm{mg} / \mathrm{kg}$ in saline) was administered by intravenous bolus injection to adult male WT $(N=9)$ and $\mathrm{KO}(N=8)$ mice. (B) Adult male WT $(N=6)$ and $\mathrm{KO}(N=6)$ mice were administered rosuvastatin by oral gavage $(10 \mathrm{mg} / \mathrm{kg}$ in $0.5 \%$ hydroxypropylmethylcellulose). Plasma was obtained at various time intervals by saphenous venous sampling and rosuvastatin concentrations were determined by LC-MS/MS. Plasma concentrations are shown as mean \pm S.E.M. 
TABLE 2

Rosuvastatin pharmacokinetic parameters

\begin{tabular}{|c|c|c|c|c|}
\hline \multirow{2}{*}{ Pharmacokinetic Parameter } & \multicolumn{2}{|c|}{ WT Mice } & \multicolumn{2}{|c|}{ KO Mice } \\
\hline & $1 \mathrm{mg} / \mathrm{kg}$, i.v. $(N=9)$ & $10 \mathrm{mg} / \mathrm{kg}$, Orally $(N=6)$ & $1 \mathrm{mg} / \mathrm{kg}$, i.v. $(N=8)$ & $10 \mathrm{mg} / \mathrm{kg}$, Orally $(N=6)$ \\
\hline$C_{0}(\mathrm{ng} / \mathrm{ml})$ & $709 \pm 538$ & - & $501 \pm 243$ & - \\
\hline$C_{\max }(\mathrm{ng} / \mathrm{ml})$ & - & $78 \pm 77$ & - & $89 \pm 69$ \\
\hline$T_{\max }(\mathrm{h})$ & - & $0.39 \pm 0.33$ & - & $0.31 \pm 0.16$ \\
\hline $\operatorname{AUC}_{0-\text { last }}(\mathrm{ng} / \mathrm{ml} \times \mathrm{h})$ & $142 \pm 96$ & $104 \pm 48$ & $141 \pm 69$ & $113 \pm 32$ \\
\hline $\operatorname{AUC}_{0-\infty}(\mathrm{ng} / \mathrm{ml} \times \mathrm{h})$ & $143 \pm 96$ & $124 \pm 53$ & $142 \pm 69$ & $161 \pm 104$ \\
\hline $\operatorname{MRT}(\mathrm{h})$ & $0.43 \pm 0.11$ & $4.1 \pm 1.4$ & $0.52 \pm 0.17$ & $5.6 \pm 6.2$ \\
\hline$t_{1 / 2}(\mathrm{~h})$ & $0.87 \pm 0.21$ & $3.5 \pm 1.8$ & $0.95 \pm 0.32$ & $4.3 \pm 4.7$ \\
\hline$V_{\mathrm{ss}}(\mathrm{ml} / \mathrm{kg})$ & $5081 \pm 4721$ & - & $5138 \pm 4991$ & - \\
\hline $\mathrm{CL}_{\text {plasma }}(\mathrm{ml} / \mathrm{min}$ per kilogram $)$ & $181 \pm 123$ & - & $134 \pm 82$ & - \\
\hline$F(\%)$ & - & $8.7 \pm 3.7$ & - & $11.4 \pm 7.4$ \\
\hline
\end{tabular}

$F$, bioavailability; MRT, mean residence time; $V_{\mathrm{ss}}$, volume of distribution at steady state.

-, not applicable.

kidney (Fig. 2D). This suggests that the pharmacokinetic effects of OATP2B1 gene disruption are without complication by compensatory changes in OATP1A/1B. However, extrapolating the role of OATP2B1 in the pharmacokinetics of drugs to humans, even with the mouse $\mathrm{KO}$ model, requires caution due to different orthology and tissue expressions of OATP1A/1B transporters, as well as potential species differences in substrate specificity. In this regard, rodent models with humanized transporter expression have been developed and used to better understand the clinical importance of OATPs in pharmacokinetics (van de Steeg et al., 2013; Higgins et al., 2014; Salphati et al., 2014).

Despite the aforementioned complexities of OATPs among species, it is remarkable that we observe clear pharmacokinetic differences for oral fexofenadine in OATP2B1 KO mice with significant reduction in both $C_{\max }$ and $\mathrm{AUC}_{0-\text { last }}$ but without differences in $T_{\max }$ and $t_{1 / 2}$ (Fig. 3B; Table 1). The clearest differences in oral fexofenadine plasma concentrations between WT and KO mice were observed within the first 15 minutes after drug administration (Fig. 3B). Hence, due to practical challenges of sampling, the rapid absorptive phase was not well characterized. After intravenous administration, we found that fexofenadine pharmacokinetics was not different in KO mice (Fig. 3A). These results persuasively indicate that OATP2B1 has presystemic effects on oral fexofenadine disposition. It is also notable that the clinical interactions between fruit juices and fexofenadine were recapitulated in WT mice, including the finding that apple juice had greater effects than grapefruit juice on systemic drug exposures (Fig. 3C). Because grapefruit juice did not affect oral absorption of fexofenadine in $\mathrm{KO}$ mice (Fig. 3D), the grapefruit juice effect in WT mice can be largely attributed to interactions with OATP2B1. KO mice remain able to absorb fexofenadine, indicating transporters aside from OATP2B1 may be involved and that these transporters may also be targets of inhibition by apple juice. Our in vitro results suggest that the other transporters facilitating fexofenadine oral absorption in mice are mOATP1A5 and mOCT1 (Fig. 4). It is interesting that rOATP1A5 and human OCT1 are inhibited by fruit juice flavonoids (Dresser et al., 2002; Mimura et al., 2015). The possibility remains that alterations in intestinal water movement caused by the high osmolarities of the AJ and GFJ vehicles used in this study ( 2794 and $2464 \mathrm{mOsm} / \mathrm{kg}$, respectively) have affected fexofenadine absorption in a similar fashion as was observed for the atenolol-AJ interaction in rats (Funai et al., 2019).

The current findings for fexofenadine in OATP2B1 KO mice should be discussed in the context of studies with other OATP knockout models. The pharmacokinetics of fexofenadine was previously examined in OATP1A/1B cluster knockout mice $\left(\right.$ Slcola/l $\left.1 b^{-1-}\right)$, which do not express mOATP1A1, mOATP1A4, mOATP1A5, mOATP1A6, or mOATP1B2 (van de Steeg et al., 2010). After intravenous and oral administration, plasma fexofenadine concentrations were significantly increased owing to reduction in hepatic uptake and clearance (van de Steeg et al., 2010). Studies in OATP1A4-deficient mice showed a lack of effect on fexofenadine clearance, suggesting that the other hepatic OATPs are important in elimination (Takano et al., 2018). The current results showing a lack of pharmacokinetic differences after intravenous dosing in OATP2B1 KO mice suggest that OATP2B1 does not appreciably contribute to hepatic fexofenadine uptake and that indeed OATP1A/1B transporters are the key determinants of liver disposition in mice. In part by monitoring portal vein drug concentrations in Slcola/ $1 b^{-/-}$mice, it was concluded that the oral absorption of fexofenadine was not dependent on OATP1A/1B transporters (van de Steeg et al., 2010), which would include fexofenadine-transporting intestinal mOATP1A5. Thus, our results suggest that mOATP2B1 partly contributed to the oral absorption of fexofenadine in Slcola $/ 1 b^{-1-}$ mice.

While we confirmed that rosuvastatin was a substrate for mOATP2B1 (as it is for human OATP2B1), neither oral nor intravenous rosuvastatin plasma pharmacokinetics was altered by deficiency in murine OATP2B1. However, it is clear that OATP1A/1B transporters are key drivers of oral and intravenous rosuvastatin pharmacokinetics in mice, as was revealed by significant increases in systemic exposures in the Slcola/l $1 b^{-1-}$ model (Iusuf et al., 2013). Mouse OATP1A/1B strongly affected rosuvastatin disposition by promoting hepatobiliary first-pass and systemic elimination (Iusuf et al., 2013); a finding that was further confirmed by examining uptake kinetics in isolated hepatocytes from Slcola $/ 1 b^{-1-}$ mice (Salphati et al., 2014). It would appear that at least mOATP1B2 and mOATP1A4 are partly involved in overall hepatocyte rosuvastatin uptake, as was exposed from pharmacokinetic studies in single gene knockout mouse models (DeGorter et al., 2012; Takano et al., 2018). Furthermore, studies with heterologous in vitro expression in HeLa, CHO and HEK293 cells demonstrated that rosuvastatin was a substrate for rOATP1A1, rOATP1A4, and rOATP1B2 (Ho et al., 2006; Ishida et al., 2018). It was also noted that the intestinal absorption of rosuvastatin was not impaired in Slcola/1 $b^{-1-}$ mice (Iusuf et al., 2013). This finding indicates that intestinal mOATP1A5 is not a major determinant of rosuvastatin oral absorption in mice, although rosuvastatin was shown to be a substrate for rOATP1A5 (Ho et al., 2006) and mOATP1A5 (data not shown). Our current findings with $\mathrm{KO}$ mice further clarify that intestinal mOATP2B 1 is not involved in the rapid oral absorption of rosuvastatin. Collectively, it seems likely that yet-to-bedetermined, non-OATP transporters promote oral rosuvastatin absorption in mice. In humans, OATP2B1 may be involved in oral rosuvastatin absorption, as indicated in the clinical ronacalceret pharmacokinetic interaction study (Johnson et al., 2017). However, a lack of significant clinical grapefruit juice pharmacokinetic interaction (Kashihara et al., 2017) 
also implies that OATP2B1 is not a major determinant of oral rosuvastatin absorption in humans.

As we demonstrate for fexofenadine, the expression of OATP2B1 in the small intestine has pharmacokinetic significance. However, although the liver highly expresses OATP2B1, a role for this transporter in hepatic disposition appears minimal, at least for fexofenadine and rosuvastatin in mice. Therefore, it is interesting that in humans the protein expression of OATP2B1 can approach that of OATP1B1 (McFeely et al., 2019), but OATP2B1 has not generally been considered a quantitative contributor to overall hepatic rosuvastatin uptake in humans (Kitamura et al., 2008; Bosgra et al., 2014). Recently, the tyrosine kinase inhibitor erlotinib was found to be a substrate of OATP2B1 but not OATP1B1 or OATP1B3 (Bauer et al., 2018). Importantly, positron emission tomography studies in humans with microdoses and therapeutic doses of $\left[{ }^{11} \mathrm{C}\right]$-erlotinib indicate that this compound may be a useful probe substrate to examine the drug-drug interactions with liver OATP2B1 (Bauer et al., 2018). Therefore, additional studies are necessary to determine the pharmacokinetic impact of OATP2B1 in the liver (as well as other tissues that express the transporter such as the kidney and lung) and at the bloodbrain barrier.

In conclusion, we found that the pharmacokinetic effects of oral but not intravenous fexofenadine are influenced by OATP2B1 in a wholebody knockout mouse model. Studies with fruit juice coadministration provided additional evidence for a role of intestinal OATP2B1 in determining fexofenadine bioavailability and as a target for food-drug interactions. In addition, with the KO model, we demonstrate a lack of in vivo impact for OATP2B1 in the disposition of another substrate, rosuvastatin. It is expected that the $\mathrm{KO}$ mouse model will serve as a valuable tool to understand the in vivo relevance of OATP2B1, predict human drug disposition, and provide reasons for in vitro/ clinical disconnect.

\section{Authorship Contributions}

Participated in research design: Medwid, Li, Knauer, Dresser, Schwarz, Kim, Tirona.

Conducted experiments: Medwid, Li, Knauer, Lin, Mansell, Schmerk, Zhu, Griffin, Yousif, Schwarz, Tirona.

Performed data analysis: Medwid, Li, Knauer, Tirona.

Wrote or contributed to the writing of the manuscript: Medwid, Li, Knauer, Tirona.

\section{References}

Akamine Y, Miura M, Sunagawa S, Kagaya H, Yasui-Furukori N, and Uno T (2010) Influence of drug-transporter polymorphisms on the pharmacokinetics of fexofenadine enantiomers. Xenobiotica 40:782-789.

Bailey DG, Dresser GK, Leake BF, and Kim RB (2007) Naringin is a major and selective clinical inhibitor of organic anion-transporting polypeptide 1A2 (OATP1A2) in grapefruit juice. Clin Pharmacol Ther 81:495-502.

Bauer M, Matsuda A, Wulkersdorfer B, Philippe C, Traxl A, Özvegy-Laczka C, Stanek J, Nics L, Klebermass EM, Poschner S, et al. (2018) Influence of OATPs on hepatic disposition of erlotinib measured with positron emission tomography. Clin Pharmacol Ther 104:139-147.

Bosgra S, van de Steeg E, Vlaming ML, Verhoeckx KC, Huisman MT, Verwei M, and Wortelboe HM (2014) Predicting carrier-mediated hepatic disposition of rosuvastatin in man by scaling from individual transfected cell-lines in vitro using absolute transporter protein quantification and PBPK modeling. Eur J Pharm Sci 65:156-166.

Cvetkovic M, Leake B, Fromm MF, Wilkinson GR, and Kim RB (1999) OATP and P-glycoprotein transporters mediate the cellular uptake and excretion of fexofenadine. Drug Metab Dispos 27: 866-871.

DeGorter MK, Tirona RG, Schwarz UI, Choi YH, Dresser GK, Suskin N, Myers K, Zou G, Iwuchukwu O, Wei WQ, et al. (2013) Clinical and pharmacogenetic predictors of circulating atorvastatin and rosuvastatin concentrations in routine clinical care. Circ Cardiovasc Genet $\mathbf{6}$ : 400-408.

DeGorter MK, Urquhart BL, Gradhand U, Tirona RG, and Kim RB (2012) Disposition of atorvastatin, rosuvastatin, and simvastatin in Oatp1b2-/- mice and intraindividual variability in human subjects. J Clin Pharmacol 52:1689-1697.

Dresser GK, Bailey DG, Leake BF, Schwarz UI, Dawson PA, Freeman DJ, and Kim RB (2002) Fruit juices inhibit organic anion transporting polypeptide-mediated drug uptake to decrease the oral availability of fexofenadine. Clin Pharmacol Ther 71:11-20.

Drozdzik M, Gröer C, Penski J, Lapczuk J, Ostrowski M, Lai Y, Prasad B, Unadkat JD, Siegmund W, and Oswald S (2014) Protein abundance of clinically relevant multidrug transporters along the entire length of the human intestine. Mol Pharm 11:3547-3555.
Funai Y, Shirasaka Y, Ishihara M, Takemura M, Ichijo K, Kishimoto H, and Inoue K (2019) Effect of osmolality on the pharmacokinetic interaction between apple juice and atenolol in rats. Drug Metab Dispos 47:386-391.

Glaeser H, Bailey DG, Dresser GK, Gregor JC, Schwarz UI, McGrath JS, Jolicoeur E, Lee W, Leake BF, Tirona RG, et al. (2007) Intestinal drug transporter expression and the impact of grapefruit juice in humans. Clin Pharmacol Ther 81:362-370.

Grube M, Köck K, Oswald S, Draber K, Meissner K, Eckel L, Böhm M, Felix SB, Vogelgesang S, Jedlitschky G, et al. (2006) Organic anion transporting polypeptide $2 \mathrm{~B} 1$ is a high-affinity transporter for atorvastatin and is expressed in the human heart. Clin Pharmacol Ther 80:607-620.

Hagenbuch B and Stieger B (2013) The SLCO (former SLC21) superfamily of transporters. Mol Aspects Med 34:396-412.

Higgins JW, Bao JQ, Ke AB, Manro JR, Fallon JK, Smith PC, and Zamek-Gliszczynski MJ (2014) Utility of Oatp1a/1b-knockout and OATP1B1/3-humanized mice in the study of OATPmediated pharmacokinetics and tissue distribution: case studies with pravastatin, atorvastatin, simvastatin, and carboxydichlorofluorescein. Drug Metab Dispos 42:182-192.

Ho RH, Tirona RG, Leake BF, Glaeser H, Lee W, Lemke CJ, Wang Y, and Kim RB (2006) Drug and bile acid transporters in rosuvastatin hepatic uptake: function, expression, and pharmacogenetics. Gastroenterology 130:1793-1806.

Hussner J, Begunk R, Boettcher K, Gliesche DG, Prestin K, and Meyer Zu Schwabedissen HE (2015) Expression of OATP2B1 as determinant of drug effects in the microcompartment of the coronary artery. Vascul Pharmacol 72:25-34.

Imanaga J, Kotegawa T, Imai H, Tsutsumi K, Yoshizato T, Ohyama T, Shirasaka Y, Tamai I, Tateishi T, and Ohashi K (2011) The effects of the SLCO2Bl c.1457C $>$ T polymorphism and apple juice on the pharmacokinetics of fexofenadine and midazolam in humans. Pharmacogenet Genomics 21:84-93.

Ishida K, Ullah M, Tóth B, Juhasz V, and Unadkat JD (2018) Successful prediction of in vivo hepatobiliary clearances and hepatic concentrations of rosuvastatin using sandwich-cultured rat hepatocytes, transporter-expressing cell lines, and quantitative proteomics. Drug Metab Dispos 46:66-74.

Iusuf D, van Esch A, Hobbs M, Taylor M, Kenworthy KE, van de Steeg E, Wagenaar E, and Schinkel AH (2013) Murine Oatp1a/1b uptake transporters control rosuvastatin systemic exposure without affecting its apparent liver exposure. Mol Pharmacol 83:919-929.

Jeon H, Jang IJ, Lee S, Ohashi K, Kotegawa T, Ieiri I, Cho JY, Yoon SH, Shin SG, Yu KS, et al. (2013) Apple juice greatly reduces systemic exposure to atenolol. Br J Clin Pharmacol 75: 172-179.

Johnson M, Patel D, Matheny C, Ho M, Chen L, and Ellens H (2017) Inhibition of intestinal OATP2B1 by the calcium receptor antagonist ronacaleret results in a significant drug-drug interaction by causing a 2-fold decrease in exposure of rosuvastatin. Drug Metab Dispos 45:27-34

Johnston RA, Rawling T, Chan T, Zhou F, and Murray M (2014) Selective inhibition of human solute carrier transporters by multikinase inhibitors. Drug Metab Dispos 42:1851-1857.

Kashihara Y, Ieiri I, Yoshikado T, Maeda K, Fukae M, Kimura M, Hirota T, Matsuki S, Irie S, Izumi N, et al. (2017) Small-dosing clinical study: pharmacokinetic, pharmacogenomic (SLCO2B1 and $A B C G 2$ ), and interaction (atorvastatin and grapefruit juice) profiles of 5 probes for OATP2B1 and BCRP. J Pharm Sci 106:2688-2694.

Keiser M, Kaltheuner L, Wildberg C, Müller J, Grube M, Partecke LI, Heidecke CD, and Oswald S (2017) The organic anion-transporting peptide $2 \mathrm{~B} 1$ is localized in the basolateral membrane of the human jejunum and caco-2 monolayers. J Pharm Sci 106:2657-2663.

Kekuda R, Prasad PD, Wu X, Wang H, Fei YJ, Leibach FH, and Ganapathy V (1998) Cloning and functional characterization of a potential-sensitive, polyspecific organic cation transporter (OCT3) most abundantly expressed in placenta. J Biol Chem 273:15971-15979.

Kim M, Deacon P, Tirona RG, Kim RB, Pin CL, Meyer Zu Schwabedissen HE, Wang R, and Schwarz UI (2017) Characterization of OATP1B3 and OATP2B1 transporter expression in the islet of the adult human pancreas. Histochem Cell Biol 148:345-357.

Kitamura S, Maeda K, Wang Y, and Sugiyama Y (2008) Involvement of multiple transporters in the hepatobiliary transport of rosuvastatin. Drug Metab Dispos 36:2014-2023.

Knauer MJ, Girdwood AJ, Kim RB, and Tirona RG (2013) Transport function and transcriptional regulation of a liver-enriched human organic anion transporting polypeptide $2 \mathrm{~B} 1$ transcriptional start site variant. Mol Pharmacol 83:1218-1228.

Knauer MJ, Urquhart BL, Meyer zu Schwabedissen HE, Schwarz UI, Lemke CJ, Leake BF, Kim RB, and Tirona RG (2010) Human skeletal muscle drug transporters determine local exposure and toxicity of statins. Circ Res 106:297-306.

Kobayashi D, Nozawa T, Imai K, Nezu J, Tsuji A, and Tamai I (2003) Involvement of human organic anion transporting polypeptide OATP-B (SLC21A9) in pH-dependent transport across intestinal apical membrane. J Pharmacol Exp Ther 306:703-708.

Kullak-Ublick GA, Ismair MG, Stieger B, Landmann L, Huber R, Pizzagalli F, Fattinger K, Meier PJ, and Hagenbuch B (2001) Organic anion-transporting polypeptide B (OATP-B) and its functional comparison with three other OATPs of human liver. Gastroenterology 120:525-533.

Lilja JJ, Backman JT, Laitila J, Luurila H, and Neuvonen PJ (2003) Itraconazole increases but grapefruit juice greatly decreases plasma concentrations of celiprolol. Clin Pharmacol Ther 73: 192-198.

Lilja JJ, Kivistö KT, and Neuvonen PJ (1999) Grapefruit juice increases serum concentrations of atorvastatin and has no effect on pravastatin. Clin Pharmacol Ther 66:118-127.

Lilja JJ, Laitinen K, and Neuvonen PJ (2005) Effects of grapefruit juice on the absorption of levothyroxine. Br J Clin Pharmacol 60:337-341.

McFeely SJ, Wu L, Ritchie TK, and Unadkat J (2019) Organic anion transporting polypeptide 2B1 -more than a glass-full of drug interactions. Pharmacol Ther 196:204-215.

Mimura Y, Yasujima T, Ohta K, Inoue K, and Yuasa H (2015) Functional identification of organic cation transporter 1 as an atenolol transporter sensitive to flavonoids. Biochem Biophys Rep 2: $166-171$.

Mimura Y, Yasujima T, Ohta K, Inoue K, and Yuasa H (2017) Functional identification of plasma membrane monoamine transporter (PMAT/SLC29A4) as an atenolol transporter sensitive to flavonoids contained in apple juice. J Pharm Sci 106:2592-2598.

Ming X, Knight BM, and Thakker DR (2011) Vectorial transport of fexofenadine across Caco-2 cells: involvement of apical uptake and basolateral efflux transporters. Mol Pharm 8:1677-1686

Mooij MG, de Koning BE, Lindenbergh-Kortleve DJ, Simons-Oosterhuis Y, van Groen BD, Tibboel D, Samsom JN, and de Wildt SN (2016) Human intestinal PEPT1 transporter expression and localization in preterm and term infants. Drug Metab Dispos 44:1014-1019.

Nakano T, Katsuki S, Chen M, Decano JL, Halu A, Lee LH, Pestana DVS, Kum AST, Kuromoto RK, Golden WS, et al. (2019) Uremic toxin indoxyl sulfate promotes proinflammatory macrophage activation via the interplay of OATP2B1 and Dll4-notch signaling. Circulation 139:78-96. 
Niessen J, Jedlitschky G, Grube M, Bien S, Schwertz H, Ohtsuki S, Kawakami H, Kamiie J, Oswald S, Starke K, et al. (2009) Human platelets express organic anion-transporting peptide 2B1, an uptake transporter for atorvastatin. Drug Metab Dispos 37:1129-1137.

Nozawa T, Imai K, Nezu J, Tsuji A, and Tamai I (2004) Functional characterization of pH-sensitive organic anion transporting polypeptide OATP-B in human. J Pharmacol Exp Ther 308:438-445.

Oswald S (2019) Organic anion transporting polypeptide (OATP) transporter expression, localization and function in the human intestine. Pharmacol Ther 195:39-53.

Salphati L, Chu X, Chen L, Prasad B, Dallas S, Evers R, Mamaril-Fishman D, Geier EG, Kehler J, Kunta J, et al. (2014) Evaluation of organic anion transporting polypeptide 1B1 and 1B3 humanized mice as a translational model to study the pharmacokinetics of statins. Drug Metab Dispos 42:1301-1313.

Satoh H, Yamashita F, Tsujimoto M, Murakami H, Koyabu N, Ohtani H, and Sawada Y (2005) Citrus juices inhibit the function of human organic anion-transporting polypeptide OATP-B. Drug Metab Dispos 33:518-523.

Schwarz UI, Seemann D, Oertel R, Miehlke S, Kuhlisch E, Fromm MF, Kim RB, Bailey DG, and Kirch W (2005) Grapefruit juice ingestion significantly reduces talinolol bioavailability. Clin Pharmacol Ther 77:291-301.

Seki S, Kobayashi M, Itagaki S, Hirano T, and Iseki K (2009) Contribution of organic anion transporting polypeptide OATP2B1 to amiodarone accumulation in lung epithelial cells. Biochim Biophys Acta 1788:911-917.

Shimizu M, Fuse K, Okudaira K, Nishigaki R, Maeda K, Kusuhara H, and Sugiyama Y (2005) Contribution of OATP (organic anion-transporting polypeptide) family transporters to the hepatic uptake of fexofenadine in humans. Drug Metab Dispos 33:1477-1481.

Shirasaka Y, Mori T, Murata Y, Nakanishi T, and Tamai I (2014) Substrate- and dose-dependent drug interactions with grapefruit juice caused by multiple binding sites on OATP2B1. Pharm Res 31:2035-2043.

Shirasaka Y, Shichiri M, Mori T, Nakanishi T, and Tamai I (2013) Major active components in grapefruit, orange, and apple juices responsible for OATP2B1-mediated drug interactions. J Pharm Sci 102:3418-3426.

St-Pierre MV, Hagenbuch B, Ugele B, Meier PJ, and Stallmach T (2002) Characterization of an organic anion-transporting polypeptide (OATP-B) in human placenta. J Clin Endocrinol Metab 87:1856-1863.

Takano J, Maeda K, Kusuhara H, and Sugiyama Y (2018) Organic anion transporting polypeptide 1a4 is responsible for the hepatic uptake of cardiac glycosides in mice. Drug Metab Dispos 46:652-657.

Tamai I and Nakanishi T (2013) OATP transporter-mediated drug absorption and interaction. Curr Opin Pharmacol 13:859-863.

Tamai I, Nezu J, Uchino H, Sai Y, Oku A, Shimane M, and Tsuji A (2000) Molecular identification and characterization of novel members of the human organic anion transporter (OATP) family. Biochem Biophys Res Commun 273:251-260.
Tapaninen T, Neuvonen PJ, and Niemi M (2011) Orange and apple juice greatly reduce the plasma concentrations of the OATP2B1 substrate aliskiren. Br J Clin Pharmacol 71:718-726.

Tirona RG and Kim RB (2014) Organic anion-transporting polypeptides, in Drug Transporters: Molecular Characterization and Role in Drug Disposition (You G and Morris ME eds) pp 43-46, John Wiley \& Sons, Hoboken, NJ.

van de Steeg E, van Esch A, Wagenaar E, Kenworthy KE, and Schinkel AH (2013) Influence of human OATP1B1, OATP1B3, and OATP1A2 on the pharmacokinetics of methotrexate and paclitaxel in humanized transgenic mice. Clin Cancer Res 19:821-832.

van de Steeg E, Wagenaar E, van der Kruijssen CM, Burggraaff JE, de Waart DR, Elferink RP, Kenworthy KE, and Schinkel AH (2010) Organic anion transporting polypeptide 1a/1bknockout mice provide insights into hepatic handling of bilirubin, bile acids, and drugs. $J$ Clin Invest 120:2942-2952.

Visentin M, Chang MH, Romero MF, Zhao R, and Goldman ID (2012) Substrate- and pH-specific antifolate transport mediated by organic anion-transporting polypeptide 2B1 (OATP2B1SLCO2B1). Mol Pharmacol 81:134-142.

Yonemura T, Okada N, Sagane K, Okamiya K, Ozaki H, Iida T, Yamada H, and Yagura H (2018) Effects of milk or apple juice ingestion on the pharmacokinetics of elvitegravir and cobicistat in healthy Japanese male volunteers: a randomized, single-dose, three-way crossover study. Clin Pharmacol Drug Dev 7:737-743.

Yu J, Zhou Z, Tay-Sontheimer J, Levy RH, and Ragueneau-Majlessi I (2017) Intestinal drug interactions mediated by OATPs: a systematic review of preclinical and clinical findings. J Pharm Sci 106:2312-2325.

Zamek-Gliszczynski MJ, Taub ME, Chothe PP, Chu X, Giacomini KM, Kim RB, Ray AS, Stocker SL, Unadkat JD, Wittwer MB, et al.; International Transporter Consortium (2018) Transporters in drug development: 2018 ITC recommendations for transporters of emerging clinical importance. Clin Pharmacol Ther 104:890-899.

Zhou M, Xia L, and Wang J (2007) Metformin transport by a newly cloned proton-stimulated organic cation transporter (plasma membrane monoamine transporter) expressed in human intestine. Drug Metab Dispos 35:1956-1962.

Address correspondence to: Dr. Rommel G. Tirona, Department of Physiology and Pharmacology, University of Western Ontario, 339 Windermere Road, London, ON, Canada N6A 5A5. E-mail: rommel.tirona@schulich.uwo.ca 